\title{
Taxonomic revision of tuberosum species-group of Simulium (Simulium) in Sabah and Sarawak, Malaysia (Diptera: Simuliidae)
}

\author{
Hiroyuki TAKAOKA \\ Department of Infectious Disease Control, Faculty of Medicine, Oita University, \\ Hasama, Yufu City, Oita, 879-5593 Japan
}

(Received: 31 January 2008; Accepted: 6 March 2008)

\begin{abstract}
In Sabah and Sarawak, Malaysia, six black fly species (two known and four new) are placed in the tuberosum species-group of the subgenus Simulium (Simulium) Latreille s. str. The male, pupa and mature larva of $S$. (S.) aeneifacies Edwards are described for the first time, S. (S.) sabahense Smart and Clifford is revised, and all the four new species are described. All the six species are morphologically very similar to one another and endemic to Borneo, thus suggesting an intra-insular speciation which has been so far known to occur very rarely in the tuberosum species-group.
\end{abstract}

Key words: Simulium, black fly, Simuliidae, tuberosum, Malaysia, holotype

The tuberosum species-group of the subgenus Simulium (Simulium) Latreille s. str., which is widely distributed in the Holarctic and Oriental Regions (Takaoka, 2003), is represented by two species in Sabah and Sarawak, Malaysia, where 20 species of black flies have been reported (Takaoka, 2001a, 2001b, 2007). In this revisionary study of the tuberosum species-group in Sabah and Sarawak, six species consisting of two known and four new species are placed in this speciesgroup using a combination of several morphological features including the relative length of the female sensory vesicle, the relative width of the male hind basitarsus, the number of enlarged facets of the male upper eye, the arrangement of the six pupal gill filaments and the shape of tubercles on the pupal thorax. At least one of the four new species is thought to have been included in $S$. (S.) sabahense Smart and Clifford which was originally described on the basis of many specimens collected from various localities in Sabah and Sarawak (Smart and Clifford, 1969).
The male, pupa and mature larva of $S$. (S.) aeneifacies Edwards originally described from a unique female specimen collected at Kamborangah (2,160 $\mathrm{m}$ in altitude), Mt. Kinabalu, Sabah (Edwards, 1933), are described for the first time.

Examined in this study were reared adults, pupae and larvae collected from Sabah and Sarawak by the author in 1998 and 2007 as well as the type specimens of the two known species loaned from the Natural History Museum, London, U.K. The terms for morphological features used here follow those of Takaoka (2003). Holotype and paratype specimens of the new species are deposited at the Department of Infectious Disease Control, Faculty of Medicine, Oita University, Oita, Japan, and some paratype specimens will be deposited in due course at Sarawak Museum, Kuching, Sabah Museum, Kota Kinabalu, and Kinabalu Conservation Center, Kinabalu Parks. 


\section{Simulium (Simulium) alberti sp. nov.}

DESCRIPTION. Female. Body length 2.1$2.3 \mathrm{~mm}$. Head. Narrower than width of thorax. Frons black, shiny, with several dark stout hairs along lateral margins and near lower margin; frontal ratio $1.35: 1.00: 1.23$; fronshead ratio $1.00: 3.84$. Fronto-ocular area (Fig. 1A) moderately developed, directed laterally or slightly upward, and with tip rounded or pointed. Clypeus black, shiny, moderately covered with dark stout hairs except central area widely bare. Labrum 0.60 times as long as clypeus. Antenna composed of scape, pedicel and 9 flagellomeres, dark brown except scape, pedicel and basal minute to whole of 1 st flagellomere yellow. Maxillary palp medium brown, composed of 5 segments, proportional lengths of $3 \mathrm{rd}, 4 \mathrm{th}$, and 5 th segments 1.00 : $1.03: 2.00$; 3rd segment (Fig. 1B) moderately enlarged; sensory vesicle (Fig. 1B) elongate, 0.59 times as long as 3rd segment, with large round opening medially. Maxillary lacinia with 15-17 inner and 18 or 19 outer teeth. Mandible with about 30 inner and 12 outer teeth. Cibarium (Fig. 1C) with about 30 vestigial minute processes. Thorax. Scutum black, shiny, moderately covered with medium to dark brown recumbent short hairs interspersed with dark brown long upright hairs on prescutellar area. Scutellum black, shiny, with dark brown long upright hairs. Postnotum black, shiny, and bare. Pleural membrane bare. Katepisternum longer than deep, dark brown to brownish-black, bare, shiny when illuminated. Legs. Foreleg: coxa whitish-yellow; trochanter light brown with base white; femur light to medium brown (usually lighter near base); tibia (Fig. 1D, E) light to dark brown with outer surface widely white; outer surface widely white sheeny when illuminated at certain angle of light; tarsus (Fig. 1F) brownishblack, with thick dorsal crest of short hairs; basitarsus moderately dilated, 5.2 times as long as greatest width. Midleg: coxa dark brown with posterolateral surface brownish-black; trochanter dark brown with base yellow; femur medium brown with apical cap dark brown; tibia (Fig. 1G) medium brown with apical cap dark brown and base white; tibia white sheeny widely on posterior surface when illuminated at certain angle of light; tarsus (Fig. 1H) medium brown except basal 5/6 of basitarsus, basal $1 / 3$ of 2 nd segment and base of 3rd seg- ment yellowish-white. Hind leg: coxa dark brown to brownish-black; trochanter yellow; femur medium brown with apical cap dark brown and base dark yellow to light brown; tibia (Fig. 1I) medium brown with apical cap dark brown and base clearly white; tibia white sheeny widely on posterior surface when illuminated at certain angle of light; tarsus (Fig. $1 \mathrm{~J}$ ) medium to dark brown except basal $3 / 4$ or little less of basitarsus and basal $1 / 2$ of 2 nd segment white; basitarsus (Fig. 1J) nearly parallel-sided, 5.73 times as long as its greatest width, 0.79 and 0.63 times as wide as greatest widths of hind tibia and femur, respectively; calcipala nearly as long as width at base, and 0.37 times as wide as greatest width of basitarsus; pedisulcus distinct; claw (Fig. 1K) simple, without tooth. Wing. Length $2.1 \mathrm{~mm}$. Costa with spinules and hairs. Subcosta haired except near apex bare. Basal section of vein $R$ bare; $\mathrm{R}_{1}$ with spinules and hairs; $\mathrm{R}_{2}$ with hairs only. Hairs at base of stem vein dark brown. Basal cell absent. Abdomen. Basal scale brownish-black, with fringe of long hairs. Dorsal surface of abdominal segments medium brown to black, with dark hairs; 2nd segment with pair of large silvery iridescent dorsolateral spots broadly connected in middle to each other; tergites 6-9 shiny. Ventral surface of abdominal segment 7 with pair of round sternal plates. Genitalia. Sternite 8 (Fig. 1L) well sclerotized, somewhat depressed medially, covered with 5-12 long and medium-long stout hairs and a few short fine hairs on each side. Ovipositor valves (Fig. 1L) nearly triangular, rounded posteromedially, membranous except inner margins weakly sclerotized, densely covered with microsetae together with $3-7$ short fine hairs; inner margins slightly concave, somewhat separated from each other. Genital fork (Fig. 1M) of inverted-Y form; stem slender and well sclerotized; arms of moderate width, each with strongly-sclerotized lateral ridge having distinct projection directed forwardly. Paraproct in ventral view (Fig. 1N) triangular, pointed posteromedially, moderately concave anterolaterally, and with strongly sclerotized anteromedial surface; paraproct in lateral view (Fig. 1O) moderately produced ventrally, 1.7 times as wide as its basal length, covered with 19-26 medium-long stout hairs and numerous short fine hairs on lateral and ventral surface. Cercus in lateral view (Fig. 1O) short, rounded posteriorly, 0.67 times as long as its greatest 


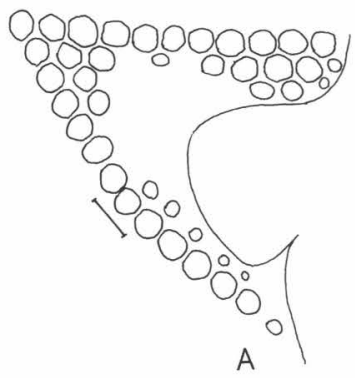

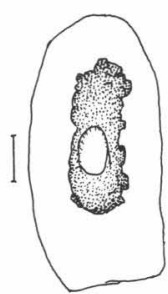

B

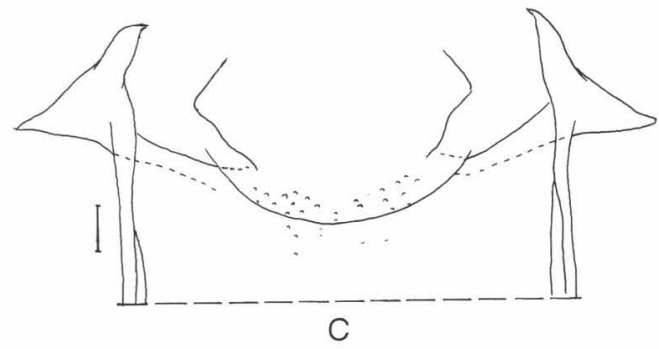

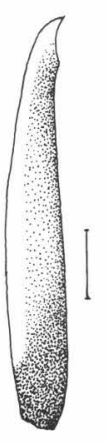

D

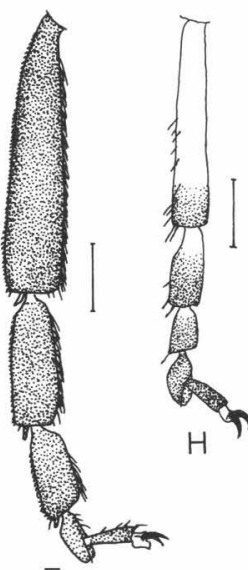

F

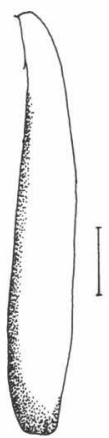

$\mathrm{E}$
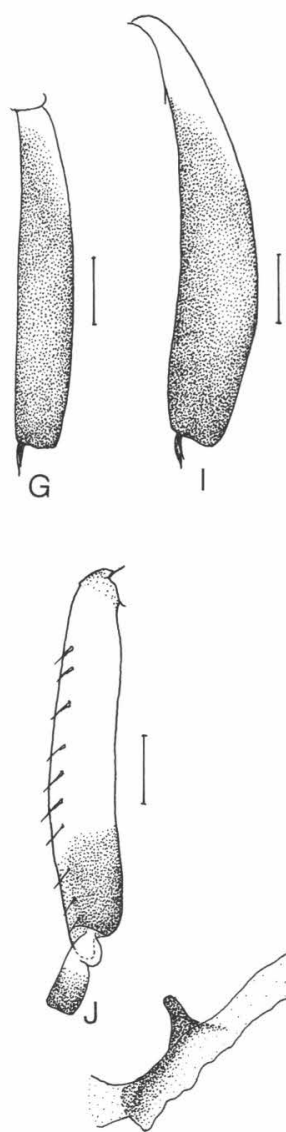
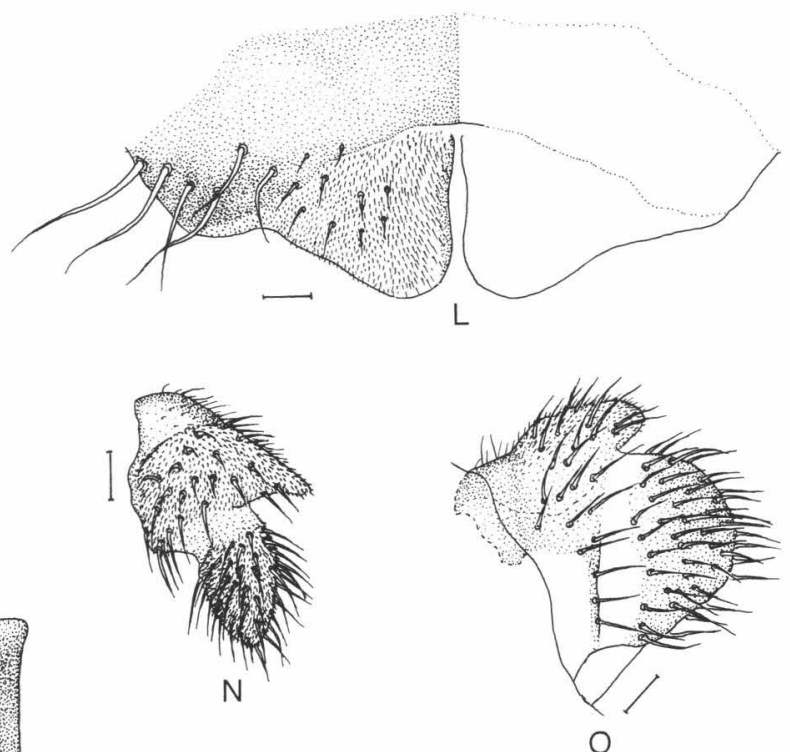

Fig. 1. Female of Simulium (Simulium) alberti sp. nov. A, fronto-ocular area (right side); B, 3rd segment of maxillary palp with sensory vesicle (right side, front view); C, cibarium; D and E, fore tibiae (D, posterior view; E, anterior view); F, fore tarsus; G, mid tibia (outer view); H, mid tarsus; I, hind tibia (outer view); J, hind basitarsus and 2nd tarsal segment (outer view); K, claw of hind leg; L, 8th sternite and ovipositor valves in situ (ventral view); $\mathrm{M}$, genital fork (ventral view); $\mathrm{N}$ and $\mathrm{O}$, paraproct and cercus in situ (N, ventral view; O, lateral view); P, spermatheca. Scale bars. $0.1 \mathrm{~mm}$ for D-J; $0.02 \mathrm{~mm}$ for $\mathrm{A}, \mathrm{B}$ and $\mathrm{L}-\mathrm{P} ; 0.01 \mathrm{~mm}$ for $\mathrm{C}$ and $\mathrm{K}$.

width, and covered with numerous mediumlong and short stout hairs. Spermatheca (Fig. 1 P) ellipsoidal, 1.25 times as long as wide, well sclerotized except duct and narrow area of juncture with duct unsclerotized, without reti- culate surface patterns; minute internal setae present; both accessory ducts subequal in diameter to each other, and slightly thicker than that of main duct.

Male. Body length $2.1-2.3 \mathrm{~mm}$.

Head. 
Slightly wider than thorax. Upper eye consisting of large facets in 18-20 vertical columns and in 20-22 horizontal rows on each side. Clypeus brownish-black, grayish pruinose, and silvery and bluish iridescent when illuminated at certain angle of light, moderately covered with dark brown long hairs though median portion widely bare longitudinally. Antenna composed of scape, pedicel and 9 flagellomeres, entirely dark brown (or dark brown except base of 1st flagellomere dark yellow); 1st flagellomere somewhat elongate, 1.78 times as long as 2nd one. Maxillary palp composed of 5 segments, proportional lengths of 3rd, 4th, and 5th segments $1.00: 1.04: 2.07$; 3rd segment (Fig. 2A) of normal size; sensory vesicle small, globular, 0.20 times as long as 3rd segment, with small opening. Thorax. Scutum black, with whitish-gray pruinose (silvery and bluish iridescent when illuminated) pattern composed of broad transverse band along anterior margin on each shoulder, broad band along each lateral margin which is connected to that on each shoulder, and large transverse band covering posterior $2 / 5$ of scutum (which is not connected to band along lateral margin at wing base); anterior pair of spots moderately separated in middle (thus middle $1 / 3$ of scutum non-pruinose); scutum densely covered with copper-colored fine short hairs interspersed with dark brown long upright hairs on prescutellar area. Scutellum brownish-black, with dark brown long erect hairs. Postnotum brownish-black, gray pruinose, and silvery and bluish iridescent when illuminated at certain angle of light. Pleural membrane and katepisternum similar to those of female. Legs. Foreleg: coxa yellowish-white; trochanter light to medium brown with base yellow; femur medium brown with apical cap dark brown; tibia (Fig. 2B, C) light to medium brown with outer surface widely white; outer surface widely white sheeny when illuminated at certain angle of light; tarsus brownish-black, with thick dorsal crest of short hairs; basitarsus moderately dilated, 6.76 times as long as its greatest width. Midleg: coxa brownish-black; trochanter medium brown with base yellow; femur medium to dark brown; tibia (Fig. 2D) medium to dark brown with base very narrowly yellow; basitarsus yellowish-white with tip medium brown; rest of tarsus medium brown except basal $1 / 4$ or $1 / 3$ of 2 nd segment yellowish-white. Hind leg: coxa brownish- black; trochanter yellow; femur medium to dark brown with base somewhat lighter; tibia (Fig. 2E) medium to dark brown with base yellow; tarsus medium brown except basal 1/2 or little more or less of basitarsus and basal $1 / 2$ of 2nd segment yellowish-white; basitarsus (Fig. 2F) greatly enlarged, gradually widened from base to apical $1 / 3$, then very slightly narrowed to apical $1 / 6$, and moderately narrowed toward tip, 3.42 times as long as its greatest width, 1.00 and 1.14 times as wide as greatest widths of hind tibia and femur, respectively; calcipala slightly shorter than its basal width, and 0.31 times as wide as greatest width of basitarsus; pedisulcus distinct. Wing. Length $1.9 \mathrm{~mm}$; other characters as in female except subcosta entirely bare. Abdomen. Basal scale brownish-black, with fringe of long hairs. Dorsal surface of abdomen brownish-black to black, with dark hairs; segments 2 and 5-7 each with pair of silvery and bluish iridescent dorsolateral spots broadly connected in middle to each other on segment 2 but narrowly so or not on other segments. Genitalia. Coxite in ventral view (Fig. 2G) nearly quadrate. Style in ventral view (Fig. 2G) elongate, longer than coxite, with apical $1 / 2$ gently curved inward, with subbasal protuberance directed mediodorsally, and with stout apical spine; style in ventrolateral view (Fig. $2 \mathrm{H}$ ) nearly parallelsided basally, then slightly narrowed toward apical $1 / 3$, and very slightly widened toward apex; style in medial view (Fig. 2I) with round subbasal protuberance having several distinct spines. Ventral plate in ventral view (Fig. 2G): body nearly quadrate though anterior margin concave, having ventrally-produced hairy median process near posterior margin, and basal arms short, stout and somewhat diverged; ventral plate in lateral view (Fig. 2K): body and ventrally-produced hairy process having weakly toothed posterolateral margins; ventral plate in end view (Fig. 2J): body and ventrally-produced median process gradually narrowed ventrally and with round apex, with weakly toothed lateral margins on basal $2 / 3$, and posterior surface very slightly concave and setose except lateral portions of basal $1 / 2$ widely bare. Median sclerite in ventral and lateral views (Fig. 2G, K) moderately sclerotized, with base located apart in front of anterior margin of ventral plate; median sclerite in end view (Fig. 2L) gradually widened toward apex. Paramere in end view (Fig. 2M) very wide 


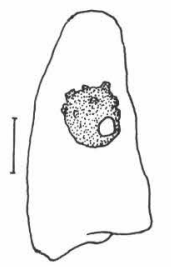

A

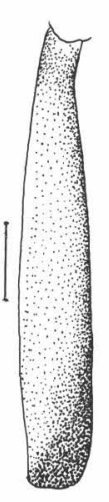

B

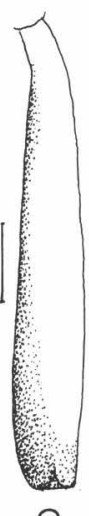

C
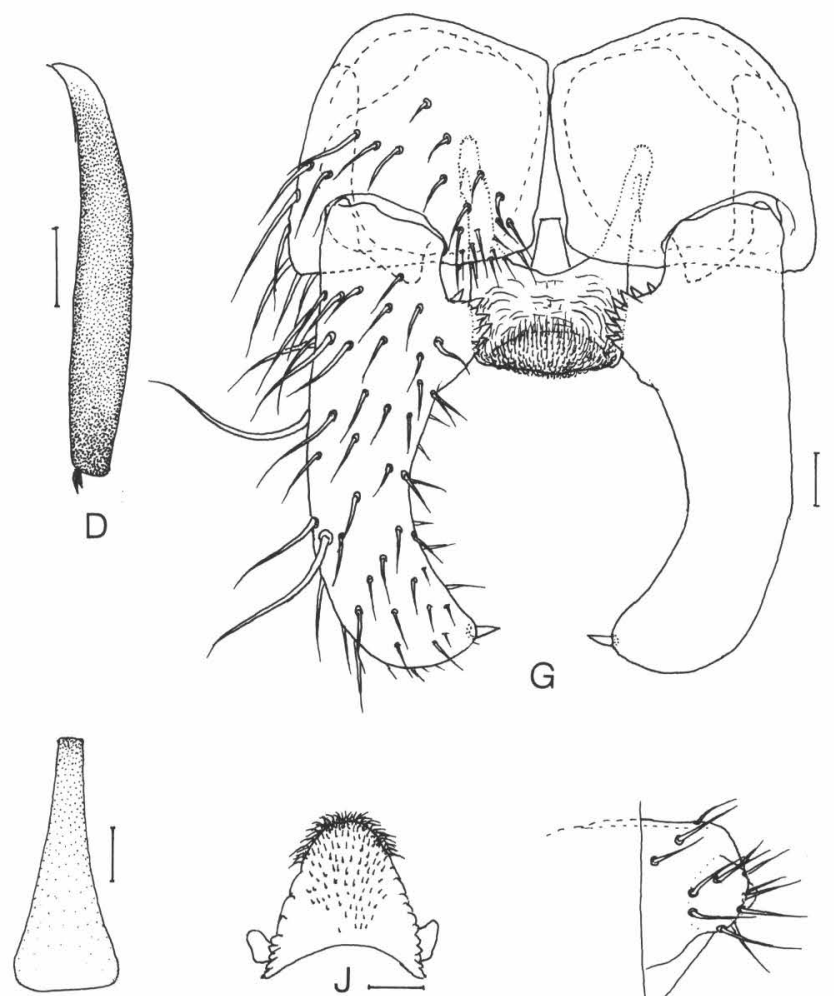

L
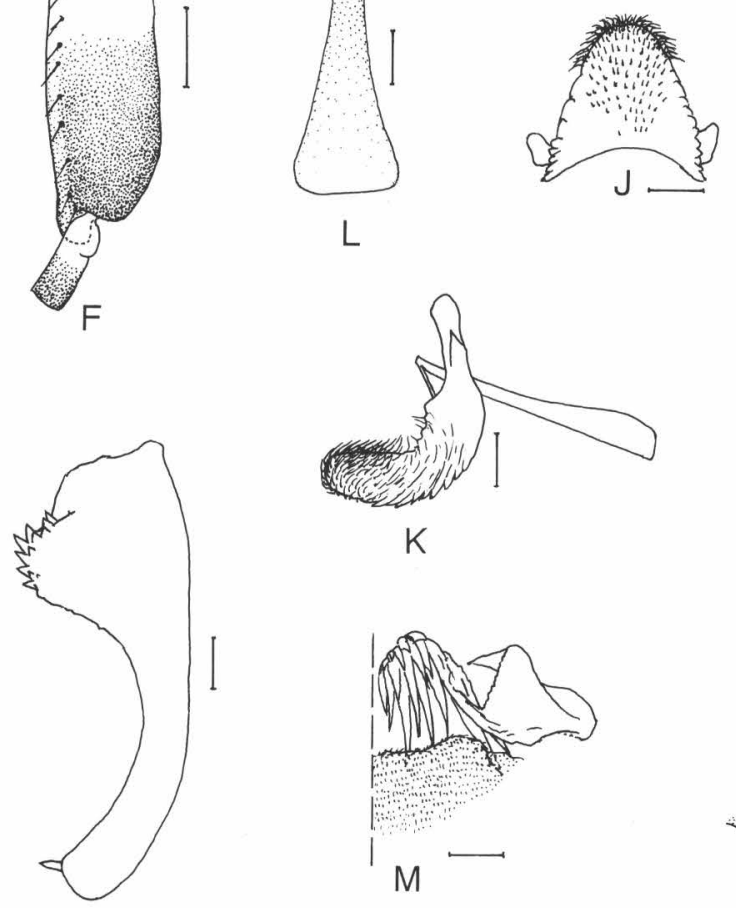

।

$\mathrm{H}$

Fig. 2. Male of Simulium (Simulium) alberti sp. nov. A. 3rd segment of maxillary palp with sensory vesicle (right side, front view); $\mathrm{B}$ and $\mathrm{C}$, fore tibiae (B, posterior view; $\mathrm{C}$, anterior view); $\mathrm{D}$, mid tibia (outer view); E, hind tibia (outer view); F, hind basitarsus and 2nd tarsal segment (outer view); G, coxites, styles, ventral plate and median sclerite in situ (ventral view); H and I, style (H, ventrolateral view; I, medial view); J, ventral plate (end view); K, ventral plate and median sclerite (lateral view); L, median sclerite (end view); M, paramere and aedeagal membrane (left half, end view); $\mathrm{N}$, dorsal plate (ventral view); $\mathrm{O}$ and $\mathrm{P}, 10$ th abdominal segment and cercus $(\mathrm{O}$, lateral view; $\mathrm{P}$, end view). Scale bars. $0.1 \mathrm{~mm}$ for $\mathrm{B}-\mathrm{F} ; 0.02 \mathrm{~mm}$ for $\mathrm{A}$ and $\mathrm{G}-\mathrm{P}$. 
basally and with several distinct parameral hooks apically. Aedeagal membrane in end view (Fig. 2M) moderately covered with minute setae; dorsal plate in end view (Fig. 2N) well sclerotized, in form of transverse narrow plate. Ventral surface of 10th abdominal segment (Fig. 2O, P) with 3 or 4 distinct hairs on each posterolateral corner. Cercus (Fig. 2O, P) rounded, with 9 or 10 distinct hairs.

Pupa. Body length (excluding gill filaments) about $2.5 \mathrm{~mm}$. Head. Integument yellowishbrown, moderately covered with round tubercles (Fig. 3A); antennal sheath almost bare with a few small tubercles: frons with 2 simple short or medium-long slender trichomes (Fig. 3B) on each side; face with 1 simple long somewhat stout trichome (Fig. 3C) on each side. Thorax. Integument yellowish-brown, moderately covered with round tubercles (Fig. 3D) except posterodorsal surface covered with smaller cone-shaped tubercles; thorax with 2 simple long stout trichomes mediodorsally (Fig. 3E), 2 simple long trichomes (1 stout, 1 somewhat stout) anterolaterally (Fig. 3F), 1 simple medium-long somewhat stout trichome posterolaterally (Fig. 3G), and 3 simple trichomes (2 long and stout, 1 medium-long and slender) ventrolaterally (Fig. $3 \mathrm{H}$ ) on each side. Gill (Fig. 3I) with 6 slender thread-like filaments in pairs; dorsal pair with medium-long stalk, middle and ventral pairs with mediumlong to long stalk, variable in length by individual pupae or even by gills of same pupae, e.g., stalk of middle pair nearly as long as that of dorsal pair (Fig. 3J) or stalk of both middle and ventral pairs more than twice as long as that of dorsal pair (Fig. 3K); stalk of dorsal pair thickest, followed by stalk of middle pair, then stalk of ventral pair thinnest; all filaments medium brown, lying vertically, and decreasing in length and thickness from dorsal to ventral; longest dorsal filament $2.2-2.5 \mathrm{~mm}$ long, and shortest ventral filament $1.0-1.3 \mathrm{~mm}$ long; stalks of dorsal and ventral pairs diverged basally at angle of about 40 degrees; cuticular surface with distinct annular ridges and furrows throughout their length, covered with minute tubercles of different sizes, relatively larger ones on ridges and smaller ones on interridge spaces. Abdomen. Dorsally, segment 1 with 1 simple slender medium-long seta (Fig. $3 \mathrm{~L}$ ) on each side; segment 2 with 6 simple slender short setae, of which 1 is slightly longer than others (Fig. 3M), on each side; seg- ments 3 and 4 each with 4 simple hooked spines and 1 simple short seta on each side; segment 5 bare; segments $6-9$ each with comblike groups of minute spines on each side, and segments 7-9 with well developed spine-combs in transverse row on each side; segment 9 with pair of triangular terminal hooks (Fig. 3N). Ventrally, segment 4 with 1 simple or bifid hooklet and a few simple short setae on each side; segment 5 with pair of bifid hooks submedially and 1 simple short seta on each side; segments 6 and 7 each with pair of bifid inner and simple or bifid outer hooks widely spaced and 1 simple short seta on each side. Grapnellike hooklets absent. Cocoon. Wall-pocketshaped, moderately woven, often with very small open spaces anteriorly, not extending ventrolaterally; individual threads visible; $2.6^{-}$ $3.1 \mathrm{~mm}$ long by $1.1-1.5 \mathrm{~mm}$ wide.

Mature larva. Body length $5.0 \mathrm{~mm}$. Thorax and abdomen (Fig. 9A-C) almost uniformly dark purplish-brown though each of abdominal segments 1-4 appearing to have broad transverse band due to partially unpigmented intersegmental areas between thoracic segment 3 and abdominal segment 5; dark broad marking on ventral surface of thoracic segment 3 narrowly connected in middle to dark marking just posterior to base of proleg and that of abdominal segment 1 . Cephalic apotome (Fig. 10A) yellow except narrow medial area along posterior margin somewhat darkened; head spots indistinct except posterior $1 / 2$ of mediolateral spot faintly positive. Lateral surface of head capsule (Fig. 10B) yellow or somewhat dark yellow except eye-spot region whitish; eyebrow distinctly defined; 1 or 2 small isolated spots below eye-spot region appearing negative. Ventral surface of head capsule (Fig. 10C) medium to dark yellow except wide area along each lateral margin of postgenal cleft yellowish-brown to light brown; transverse spot on each side of postgenal cleft negative; basal area on each side of postgenal cleft dark brown as usual. Cervical sclerite composed of 2 elongate slender pieces (anterior piece longer and darker than posterior one), not fused to occiput, moderately separated medially from each other. Antenna composed of 3 segments and apical sensillum, much longer than stem of labral fan; proportional lengths of 1 st, $2 \mathrm{nd}$, and 3rd segments $1.00: 0.96: 0.74$. Labral fan with 38 main rays. Mandible with mandibular serrations composed of 2 teeth; major and longer 

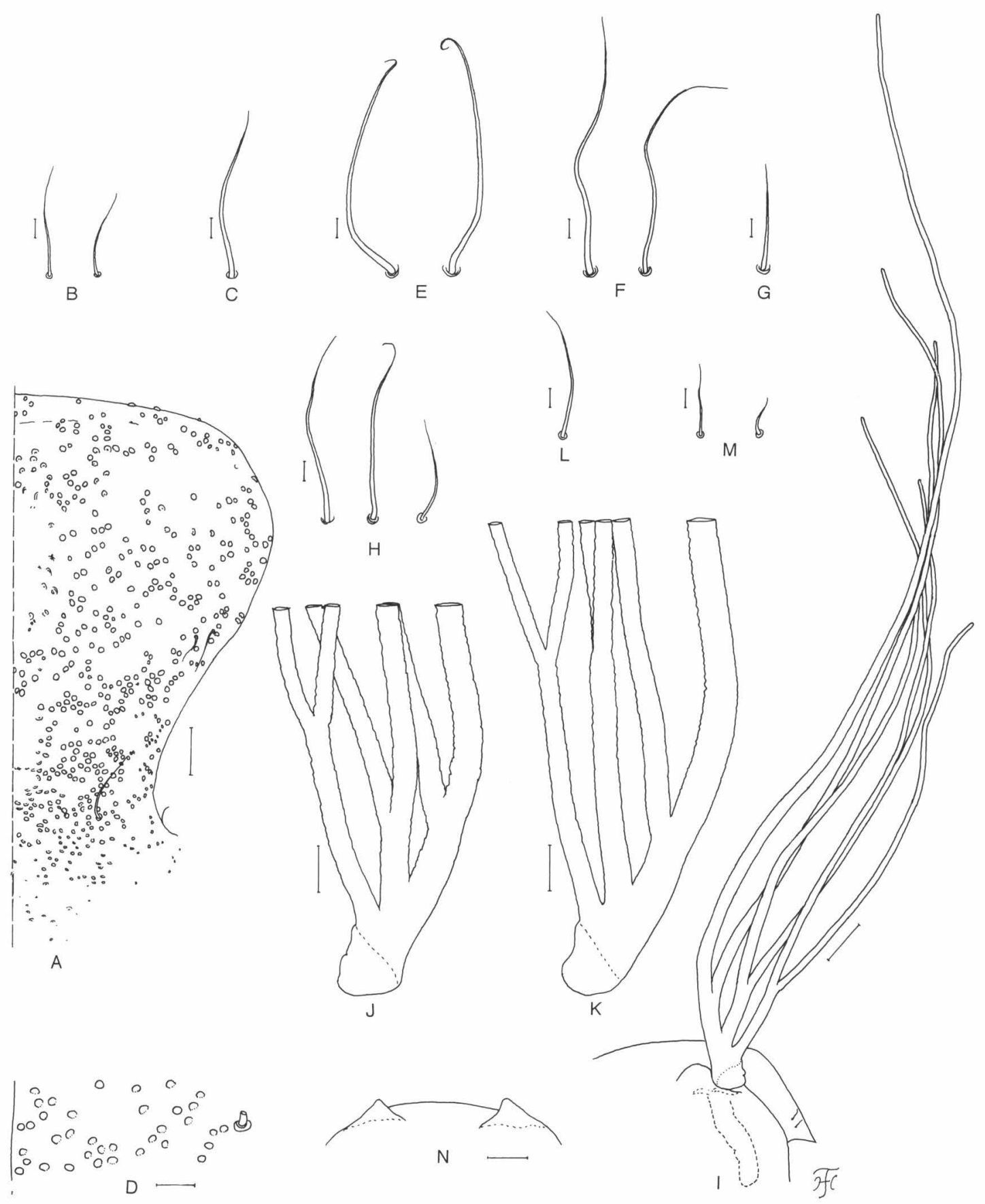

Fig. 3. Pupa of Simulium (Simulium) alberti sp. nov. A, frons (left half, front view); B, 2 frontal trichomes; C, facial trichome; D, part of mediodorsal surface of thorax showing round tubercles between mediolongitudinal line and one of mediodorsal trichomes; $\mathrm{E}-\mathrm{H}$, trichomes on thorax ( $\mathrm{E}$, mediodorsal; F, anterolateral; G, posterolateral; H, ventrolateral); I, gill filaments (right side, outer view); J and K, basal portion of gill filaments showing different lengths of stalks; L, hair-like seta on dorsal surface of abdominal segment 1; M, 1 longer seta and 1 shorter seta on dorsal surface of abdominal segment 2; N, terminal hooks (dorsal view). Scale bars. $0.1 \mathrm{~mm}$ for I; $0.05 \mathrm{~mm}$ for A, J and K; $0.02 \mathrm{~mm}$ for $\mathrm{D}$ and $\mathrm{N} ; 0.01 \mathrm{~mm}$ for $\mathrm{B}, \mathrm{C}, \mathrm{E}-\mathrm{H}, \mathrm{L}$ and $\mathrm{M}$. 
tooth at obtuse angle to mandible on apical side; 1 supernumerary serration present near shorter mandibular tooth of both mandibles; 1st comb-tooth longest, 2nd comb-tooth nearly as long as or slightly longer than 3rd one. Hypostoma with 9 anterior teeth; each corner tooth most prominent, slightly longer than median tooth, followed by outer tooth of 3 intermediate teeth, inner and middle teeth of 3 intermediate teeth subequal in length and shortest of all; lateral margins moderately serrate subapically; 5 or 6 hypostomal bristles diverging posteriorly from lateral border on each side. Postgenal cleft (Fig. 10C) long (4.00 times as long as postgenal bridge), relatively narrow (greatest width in middle 0.28 times as wide as head capsule), arrow-head-shaped, very slightly constricted basally, with sharply pointed apex. Thoracic cuticle almost bare. Abdominal cuticle almost bare except each side of anal sclerite and each lateral bulge moderately covered with short colorless setae. Rectal scales absent. Rectal organ compound, each lobe with 15-18 finger-like elongate secondary lobules. Anal sclerite X-shaped, with broadened anterior arms about 0.6 times as long as posterior ones, with wide thinlysclerotized extension between anterior arms; basal juncture area without open closed space or deep incision opening posteriorly; 2 sensilla on basal juncture area and 11 sensilla posterior to posterior arms. Last abdominal segment on each side with large bulge laterally and small one ventrolaterally, appearing to be small ventral papillae when viewed laterally. Posterior circlet with 84 rows of hooklets with up to 15 hooklets per row.

TYPE SPECIMENS. Holotype female (with its associated pupal exuviae and cocoon), reared from a pupa collected from a stream at Masilau, Kinabalu Parks, Sabah, Malaysia, 11.IX.2007, by H. Takaoka. Paratypes: 2 females, 2 males, all reared from pupae, and 2 mature larvae, same data and date as those of the holotype.

ECOLOGICAL NOTES. The pupae and larvae of this new species were collected from fallen tree leaves in a stream (width 0.5-2.0 m, water temperature $14.0^{\circ} \mathrm{C}$, shaded, altitude $1,940 \mathrm{~m}$ ) moderately flowing in a natural forest. Associated species were S. (Nevermannia) borneoense Takaoka, S. (S.) aeneifacies, S. (Gomphostilbia) sp., and S. (S.) sp.

ETYMOLOGY. The species name alberti is in honor of Dr. Lo Albert, Chief, Section of Entomology, Sabah Museum, who kindly arranged field surveys carried out in 2007.

REMARKS. This new species is most remarkable in having the elongated stalks of the pupal gill filaments (Fig. 3I-K), differing from those of most known species in the tuberosum species-group. This new species is characterized in the female by the elongate sensory vesicle (Fig. 1B), and in the male by the greater number of enlarged upper-eye facets in 18-20 vertical columns and in 20-22 horizontal rows.

The female of this new species is similar to $S$. (S.) tani described from Peninsular Malaysia (Takaoka and Davies, 1995) in having the elongate sensory vesicle (Fig. 1B) but differs from the latter species by the less dilated fore basitarsus (length/ width ratio 5.2 versus 4.4 in $S$. (S.) tani), the simple claw (claw with a minute subbasal tooth in S. (S.) tani) and the cercus of moderate size (length/width ratio 0.67 versus 0.25 in $S$. (S.) tani). The pupa of this new species differs from $S$. (S.) tani by having the elongate stalks of the gill filaments (Fig. 3I-K).

\section{Simulium (Simulium) masilauense sp. nov.}

DESCRIPTION. Female. Almost indistinguishable from that of $S$. (S.) alberti sp. nov. except following features. Body length 2.1-2.2 mm. Head. Frontal ratio $1.39: 1.00: 1.39$; frons-head ratio $1.00: 4.14$. Fronto-ocular area moderately developed, directed laterally, with tip pointed. Labrum 0.65 times as long as clypeus. Proportional lengths of $3 \mathrm{rd}, 4 \mathrm{th}$, and 5 th segments of maxillary palp $1.00: 1.18$ : 2.37. Sensory vesicle (Fig. 4A) elongate, 0.59 times as long as 3rd maxillary palpal segment. 
Maxillary lacinia with 14 or 15 inner and 20 outer teeth. Mandible with about 30 inner and 16 outer teeth. Legs. Fore basitarsus moderately dilated, 5.3 times as long as greatest width. Hind basitarsus yellowish-white on basal $2 / 3$ and medium brown on rest, 5.67 times as long as its greatest width, 0.75 and 0.65 times as wide as greatest widths of hind tibia and femur, respectively. Wing. Length 2.0-2.2 mm. Genitalia. Sternite 8 covered with 8 or 9 long and medium-long stout hairs and a few short fine hairs on each side. Ovipositor valve with 4 or 5 short fine hairs. Paraproct in lateral view covered with 30 medium-long stout hairs and numerous short fine hairs on lateral and ventral surface. Cercus in lateral view 0.50 times as long as its greatest width. Spermatheca ovoidal, 1.14 times as long as wide.

Male. Almost indistinguishable from that of S. (S.) alberti sp. nov. except following features. Body length 2.3-2.4 mm. Head. Upper eye consisting of large facets in 17 vertical columns and in 19 horizontal rows on each side. First flagellomere of antenna 1.77 times as long as 2nd one. Proportional lengths of 3rd, 4th, and 5th segments of maxillary palp $1.00: 1.19$ : 2.47. Sensory vesicle small, ellipsoidal, 0.22 times as long as 3rd segment. Legs. Fore basitarsus moderately dilated, 6.00-6.80 times as long as its greatest width. Mid tibia medium to dark brown with base very narrowly yellow to light brown. Hind basitarsus (Fig. 4B) medium brown except little less than basal $1 / 2$ yellowish-white, $3.42-3.85$ times as long as its greatest width, $0.91-1.08$ and $1.00-1.08$ times as wide as greatest widths of hind tibia and femur, respectively. Wing. Length 2.0-2.1 mm. Genitalia. Style in ventrolateral view (Fig. 4C) nearly parallel-sided basally, then slightly narrowed toward apical $1 / 3$, and almost parallel-sided to apex; Ventral surface of 10 th abdominal segment with 6 distinct hairs on each posterolateral corner. Cercus rounded, with 6 or 7 distinct hairs.

Pupa. Similar to that of $S$. (S.) alberti sp. nov. except following features. Body length (excluding gill filaments) $2.3-2.5 \mathrm{~mm}$. Head. Antennal sheath sparsely covered with small tubercles basally (Fig. 4D); frontal trichomes (Fig. 4E) slightly shorter than facial one (Fig. 4F). Thorax. Dorsomedial trichomes (Fig. 4G) somewhat shorter than anterolateral trichomes (Fig. $4 \mathrm{H}$ ) and slightly longer than post- erolateral one (Fig. 4I), and 3 ventrolateral trichomes different in length (Fig. 4J). Gill (Fig. $4 \mathrm{~K})$ with 6 slender thread-like filaments in pairs; all pairs very short-stalked; stalks of dorsal and middle pairs subequal in thickness to each other and slightly thicker than stalk of ventral pair; all filaments medium-brown, lying slightly obliquely; outer filament of dorsal pair longest (1.8-2.1 mm long) and thickest, inner filament of ventral pair shortest $(1.3-1.5 \mathrm{~mm}$ long) and thinnest, and 4 other filaments intermediate in length and thickness though inner filament of dorsal pair and outer filament of middle pair, which are subequal in length and thickness to each other, slightly longer and thicker than inner filament of middle pair and outer filament of ventral pair which are also subequal in length and thickness to each other; dorsalmost and ventralmost filaments diverged basally at angle of 60-70 degrees. Abdomen. Slender seta on dorsal surface of segment 1 (Fig. 4L) subequal in length to 1 slender seta on dorsal surface of segment 2 (Fig. 4M). Cocoon. $2.8-3.0 \mathrm{~mm}$ long by $1.0-1.3$ $\mathrm{mm}$ wide.

Mature larva. Similar to that of S. (S.) alberti sp. nov. including body color (Fig. 9D-F) except following features. Body length 4.3-5.3 $\mathrm{mm}$. Cephalic apotome (Fig. 10D) dark yellow to yellowish-brown with head spots indistinct or negative. Lateral surface of head capsule (Fig. 10E) dark yellow to light brown except eye-spot region whitish; all spots below and posterior to eye-spot region negative. Ventral surface of head capsule (Fig. 10F) dark yellow to light brown except narrow area along posterior margin of hypostoma yellowish; elongate spot on each side of postgenal cleft negative. Antenna with proportional lengths of 1 st, 2 nd, and 3rd segments $1.00: 0.95-1.05: 0.66$. Labral fan with $34-36$ main rays. Mandible without supernumerary serration. Hypostoma with 9 anterior teeth; median tooth nearly as long as or very slightly longer than each corner tooth, 3 intermediate teeth short and subequal in length to one another or outer tooth slightly longer than median and inner teeth; 4 or 5 hypostomal bristles diverging posteriorly from lateral border on each side. Postgenal cleft (Fig. 10F) long (3.94-5.50 times as long as postgenal bridge), relatively narrow (greatest width in middle $0.32-0.34$ times as wide as head capsule), slightly constricted basally. Rectal organ compound, each lobe with $12-15$ 

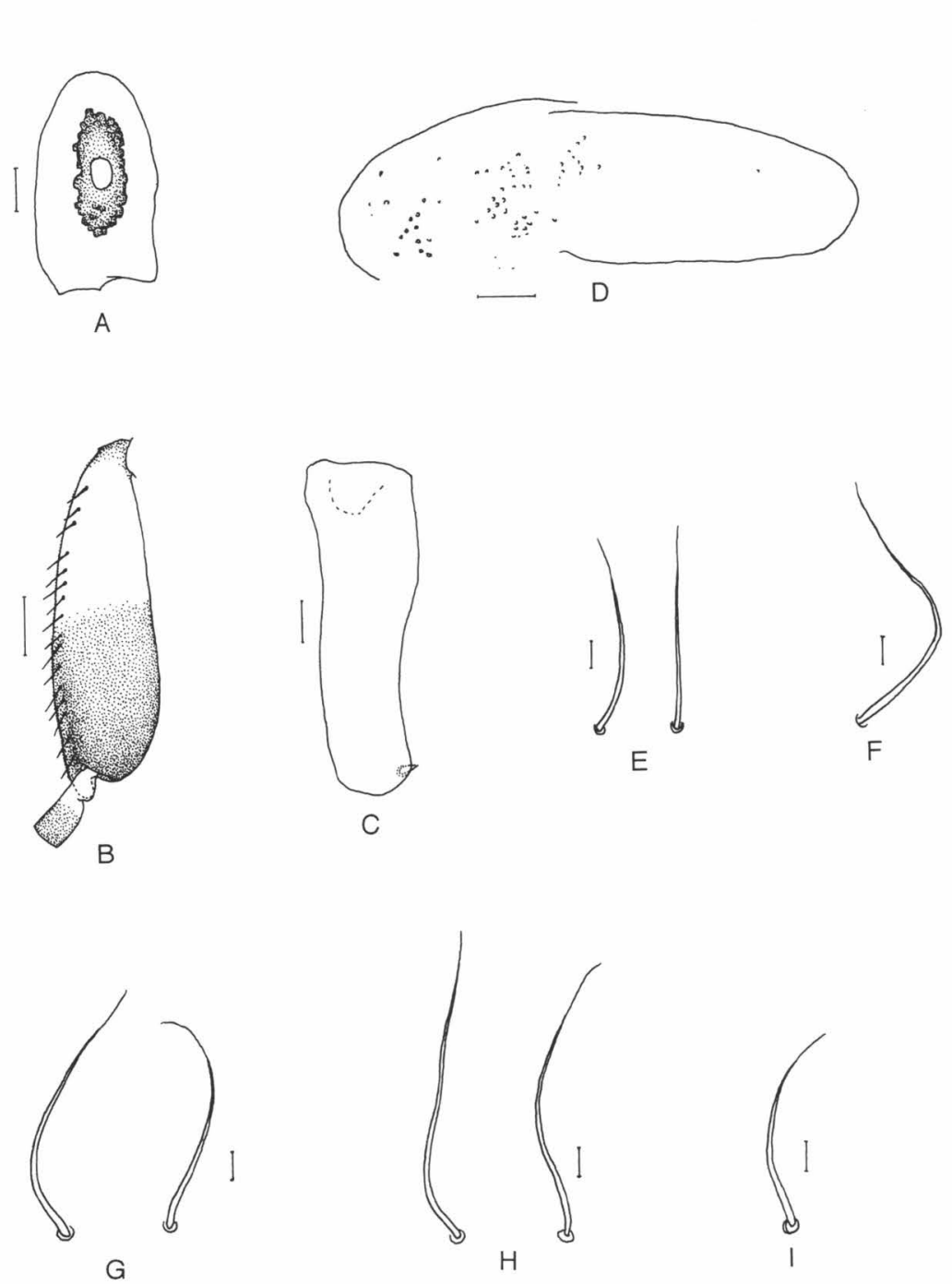

$$
\text { . }
$$
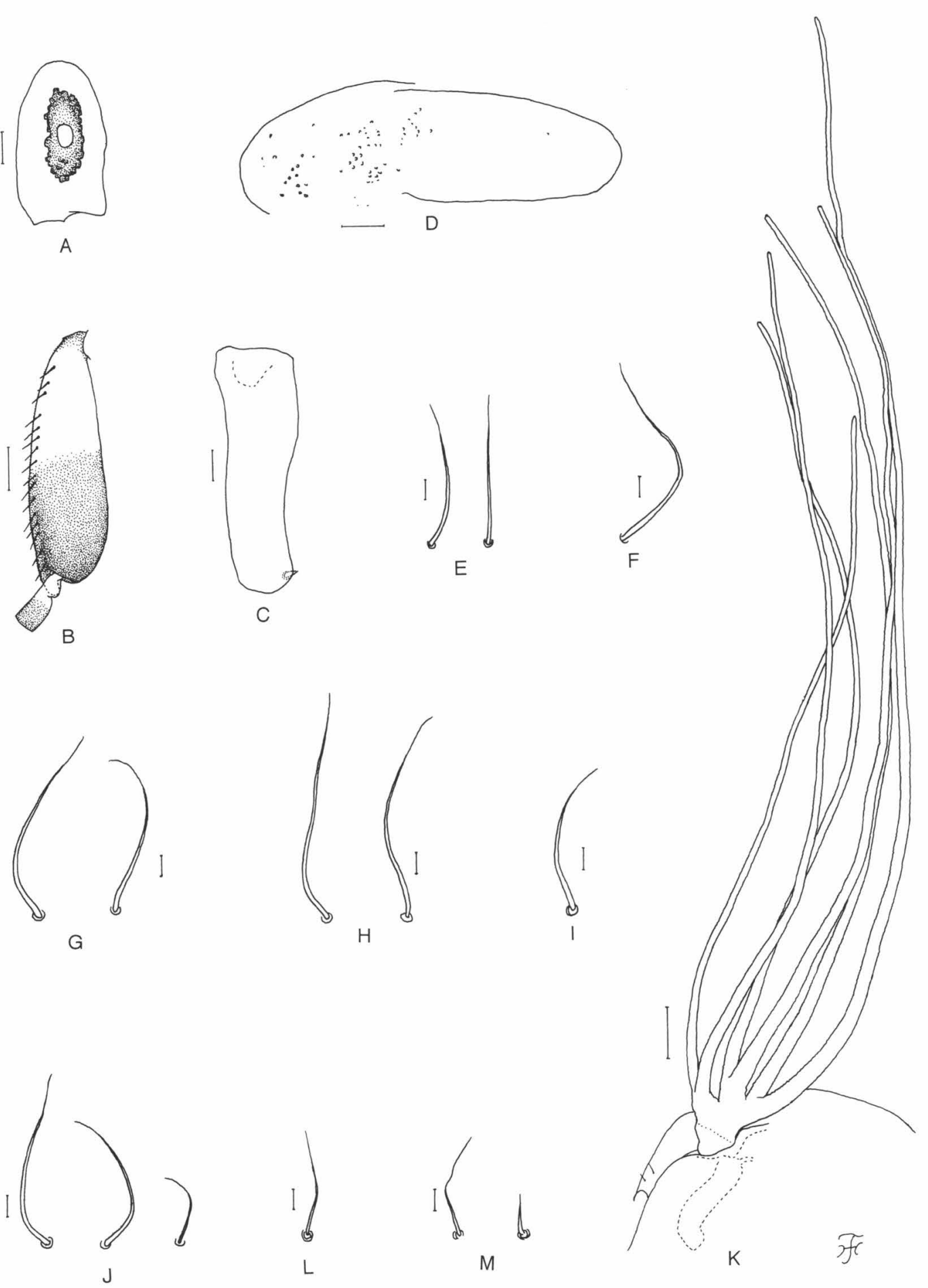
finger-like elongate secondary lobules. Anal sclerite X-shaped, with broadened anterior arms $0.6-0.7$ times as long as posterior ones; 1 or 2 sensilla on basal juncture area and 6-8 sensilla posterior to posterior arms. Posterior circlet with $74-76$ rows of hooklets with up to 14 hooklets per row.

TYPE SPECIMENS. Holotype female (with its associated pupal exuviae and cocoon), reared from a pupa collected from an irrigation stream about $100 \mathrm{~m}$ down from the Park Office, at Masilau, Sabah, Malaysia, 11. IX. 2007, by H. Takaoka. Paratypes: 3 females, 3 males (all reared from pupae), 2 mature larvae, same data and date as those of the holotype.

ECOLOGICAL NOTES. The pupae and larvae of this new species were collected from trailing grasses in an irrigation stream (width about $1 \mathrm{~m}$, water temperature $14.0^{\circ} \mathrm{C}$, exposed to sun, altitude 1,880 $\mathrm{m})$ rapidly flowing along the road. Associated species was S. (S.) keningauense sp. nov.

ETYMOLOGY. The species name masilauense refers to the locality, Masilau, where this new species was collected.

REMARKS. Simulium (S.) masilauense sp. nov. is almost indistinguishable at the adult stage from $S$. (S.) alberti sp. nov. but readily distinguished from the latter at the pupal stage by the arrangement of gill filaments (Fig. 4K) and relative length of the dorsomedial trichomes against the posterolateral trichome (Fig. 4G, I), and at the larval stage by the ventral surface of the head capsule almost uniformly darkened except near the anterior margin and elongate spots (Fig. 10F).

The female of this new species is similar to $S$. (S.) tani in having the elongate sensory vesicle (Fig. 4A) but differs from the latter species by the less dilated fore basitarsus (length/width ratio 5.3 versus 4.4 in $S$. ( $S$.) tani), the simple claw (claw with a minute subbasal tooth in $S$. (S.) tani) and the cercus of moderate size (length/ width ratio 0.50 versus 0.25 in $S$. (S.) tani). The pupa of this new species is similar to that of $S$. (S.) tani but differs by the relative length of the throacic trichomes, of which the posterolateral one is shorter than both of the dorsomedial and anterolateral trichomes (Fig. 4G-I) in this new species but longest of all (and also the dorsomedial trichomes are very short and slender) in S. (S.) tani.

\section{Simulium (Simulium) aeneifacies Edwards}

DESCRIPTION. Female. Almost indistinguishable from that of $S$. (S.) alberti sp. nov. except following features. Body length 2.0-2.2 mm. Head. Frontal ratio $1.40-1.45: 1.00: 1.25-$ 1.38; frons-head ratio $1.00: 3.72-3.89$. Frontoocular area moderately developed, directed laterally, with tip pointed. Labrum 0.56-0.64 times as long as clypeus. Proportional lengths of $3 \mathrm{rd}, 4 \mathrm{th}$, and 5 th segments of maxillary palp $1.00: 1.07-1.13: 2.11-2.41$. Sensory vesicle (Fig. 5A) small, ellipsoidal, 0.31 times as long as 3rd maxillary palpal segment, with opening of moderate size. Maxillary lacinia with 17-19 inner and 21 or 22 outer teeth. Mandible with 32 inner and 11 outer teeth. Cibarium with about 40 vestigial minute processes. Legs. Fore basitarsus moderately dilated, 4.74-4.89 times as long as greatest width. Hind trochanter yellow with anterior surface light brown. Hind basitarsus yellowish-white on basal $2 / 3$ and medium brown on rest, 5.22-5.65

Fig. 4. Simulium (Simulium) masilauense sp. nov. A, 3rd segment of female maxillary palp with sensory vesicle (right side; front view); B, basitarsus and 2nd tarsal segment of male hind leg (left side, outer view); C, style (ventrolateral view); D, antennal sheath of pupa (left side, front view); E, 2 frontal trichomes; F, facial trichome; G-J, trichomes on pupal thorax (G, mediodorsal; H, anterolateral; I, posterolateral; J, ventrolateral); K, pupal gill filaments (left side, outer view); L, hair-like seta on dorsal surface of abdominal segment 1; M, 1 longer seta and 1 shorter seta on dorsal surface of abdominal segment 2. Scale bars. $0.1 \mathrm{~mm}$ for B and $\mathrm{K} ; 0.04 \mathrm{~mm}$ for $\mathrm{D} ; 0.02 \mathrm{~mm}$ for $\mathrm{A}$ and $\mathrm{C} ; 0.01 \mathrm{~mm} \mathrm{for} \mathrm{E-J,} \mathrm{L}$ and $M$. 


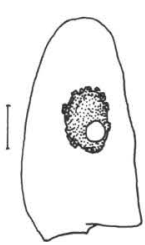

A

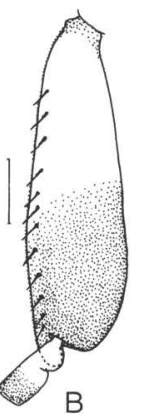

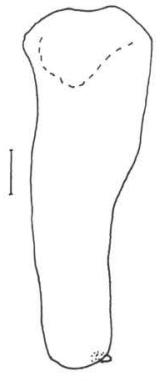

C

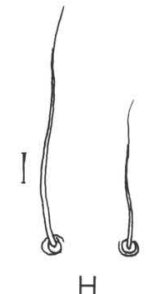

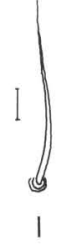
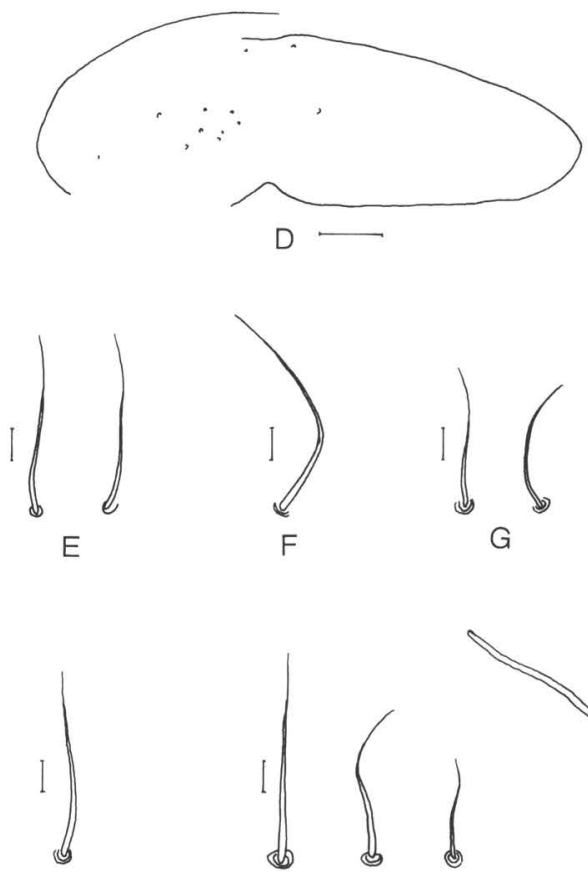

G

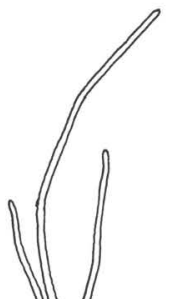

$J$

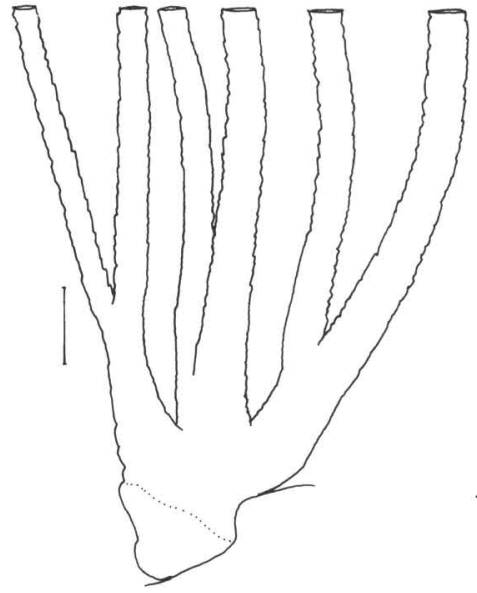

M

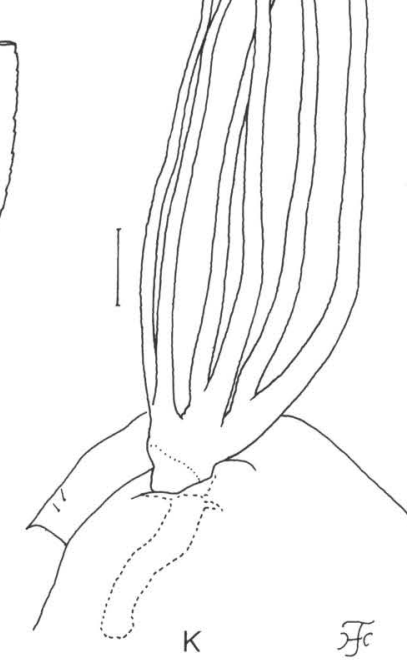

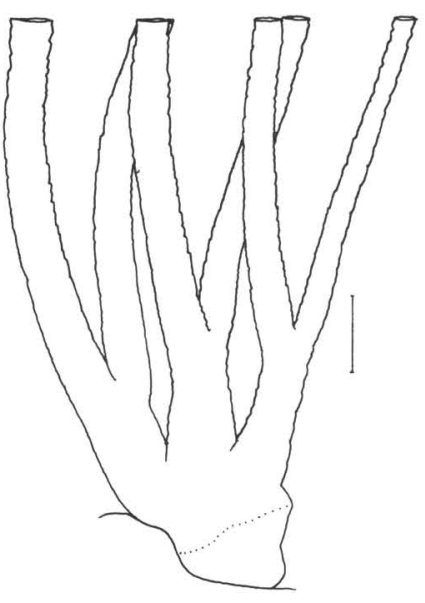

L

$\mathrm{K}$

Fic

Fig. 5. Simulium (Simulium) aeneifacies Edwards. A, 3rd segment of female maxillary palp with sensory vesicle (right side; front view); B, basitarsus and 2nd tarsal segment of male hind leg (left side, outer view); C, style (ventrolateral view); D, antennal sheath of pupa (left side, front view); E, 2 frontal trichomes; F, facial trichome; G-J, trichomes on pupal thorax (G, mediodorsal; H, anterolateral; I, posterolateral; J, ventrolateral); K, pupal gill filaments (left side, outer view); L and M, basal part of pupal gill filaments showing different lengths of stalks. Scale bars. $0.1 \mathrm{~mm}$ for B and K; $0.05 \mathrm{~mm}$ for L and $\mathrm{M} ; 0.04 \mathrm{~mm}$ for $\mathrm{D} ; 0.02 \mathrm{~mm}$ for $\mathrm{A}$ and $\mathrm{C} ; 0.01 \mathrm{~mm}$ for $\mathrm{E}-\mathrm{J}$. 
times as long as its greatest width, $0.74-0.80$ and $0.63-0.70$ times as wide as greatest widths of hind tibia and femur, respectively. Wing. Length $2.1 \mathrm{~mm}$. Genitalia. Sternite 8 covered with 6-9 long and medium-long stout hairs and a few short fine hairs on each side. Ovipositor valve with 4-8 short fine hairs. Paraproct in lateral view covered with 23 or 24 mediumlong stout hairs and numerous short fine hairs on lateral and ventral surface. Cercus in lateral view $0.53-0.57$ times as long as its greatest width. Spermatheca ovoidal, 1.12-1.15 times as long as wide.

Male. Almost indistinguishable from that of $S$. (S.) alberti sp. nov. except following features. Body length 2.2-2.4 mm. Head. Upper eye consisting of large facets in 16-18 vertical columns and in 17-20 horizontal rows on each side. First flagellomere of antenna 1.56 times as long as 2 nd one. Proportional lengths of $3 \mathrm{rd}$, 4 th, and 5th segments of maxillary palp 1.00 : $1.27: 2.50$. Sensory vesicle small, globular or ellipsoidal, 0.21 times as long as 3rd maxillary palpal segment, with opening of moderate size.

Legs. Fore basitarsus moderately dilated, 6.56 times as long as its greatest width. Mid tibia medium to dark brown with base very narrowly yellow to light brown. Hind basitarsus (Fig. $5 \mathrm{~B})$ yellowish-white on basal 1/2 and medium to dark brown on rest, gradually widened from base to little more than apical 1/3, 3.42 times as long as its greatest width, 1.10 and 1.14 times as wide as greatest widths of hind tibia and femur, respectively. Wing. Length 2.0 $\mathrm{mm}$. Genitalia. Style in ventrolateral view (Fig. 5C) slightly narrowed from middle to apex. Ventral surface of 10 th abdominal segment with 4-6 distinct hairs on each posterolateral corner. Cercus rounded, with 8 distinct hairs.

Pupa. Similar to that of $S$. (S.) masilauense sp. nov. except following features. Body length (excluding gill filaments) $2.2-2.5 \mathrm{~mm}$. Head. Frontal and facial trichomes as in Fig. 5E, F. Antennal sheath very sparsely covered with minute tubercles near base (Fig. 5D). Thorax. Both of 2 dorsomedial trichomes short and sledner (Fig. 5G), 2 anterolateral trichomes different in length (Fig. 5H), 1 posterolateral trichome (Fig. 5I) medium-long and much longer than dorsomedial ones, 3 ventrolateral trichomes different in length (Fig. 5J). Gill (Fig. $5 \mathrm{~K})$ with 6 slender thread-like filaments in pairs; all pairs short-stalked though all or 2 of 3 stalks elongated to some extent in 3 gills (Fig. $5 \mathrm{~L}, \mathrm{M}$ ); all filaments lying vertically or slightly obliquely; longest dorsal filament $1.7-2.0 \mathrm{~mm}$ long, and shortest ventral filament $0.9-1.1 \mathrm{~mm}$ long; stalks of dorsal and ventral pairs diverged basally at angle of about 45 degrees. Abdomen. Slender seta on dorsal surface of segment 1 much longer than 1 slender seta on dorsal surface of segment 2. Cocoon. 2.7-3.1 $\mathrm{mm}$ long by $1.0-1.3 \mathrm{~mm}$ wide.

Mature larva. Similar to that of $S$. (S.) alberti sp. nov. except following features. Body length 4.8-5.0 mm. Body color (Fig. 9G-I) with dark broad marking on ventral surface of thoracic segment 3 widely connected in middle to dark marking just posterior to base of proleg. Cephalic apotome (Fig. 10G) dark yellow to yellowish-brown with head spots indistinct except mediolateral spots slightly positive. Lateral surface of head capsule (Fig. 10H) dark yellow to light brown except eye-spot region whitish; all spots below and posterior to eyespot region indistinct or negative. Antenna with proportional lengths of 1st, 2 nd, and $3 \mathrm{rd}$ segments $1.00: 0.92-0.94: 0.68-0.72$. Labral fan with $38-44$ main rays. Mandible without supernumerary serration. Middle tooth of 3 intermediate teeth shortest of all; outer tooth nearly as long as or slightly longer than inner tooth; 5 or 6 hypostomal bristles diverging posteriorly from lateral border on each side. Postgenal cleft (Fig. 10I) long (2.91-3.78 times as long as postgenal bridge), relatively narrow (greatest width in middle $0.31-0.33$ times as wide as head capsule), very slightly to moderately constricted basally. Rectal organ compound, each lobe with 10-12 finger-like elongate secondary lobules. Anal sclerite X-shaped, with broadened anterior arms $0.73-0.75$ times as long as posterior ones; $0-2$ sensilla on basal juncture area and 6 sensilla posterior to posterior arms. Posterior circlet with $72-78$ rows of hooklets with up to 15 hooklets per row.

SPECIMENS EXAMINED. Holotype female (BMNH), pinned, collected at Kamborangah; 8 females, 2 males, all reared from pupae, and 3 mature larvae collected from a stream in a valley on the right side of the trecking route to $\mathrm{Mt}$. Kinabalu, $2 \mathrm{~km}$ up from the Carson Fall, Kinabalu Parks, Sabah, Malaysia, 10.IX.2007, by H. Takaoka; 6 females, 6 
males, all reared from pupae, 2 mature larvae collected from a stream at Timpohon, upstream of the water reserve just above the Carson Fall, Kinabalu Parks, 13. III.1998, by H. Takaoka and A. Takaoka; 2 females and 1 male, all reared from pupae collected from the same stream at Masilau as mentioned under $S$. (S.) alberti sp. nov.

\section{ECOLOGICAL NOTES. Near Kamboran-} gah, the pupae and larvae of this species were collected from a metal plate (about $20 \mathrm{~cm}$ long, $10 \mathrm{~cm}$ wide, $1 \mathrm{~mm}$ thick) discarded in a stream (width $0.3-0.5 \mathrm{~m}$, water temperature $12.0^{\circ} \mathrm{C}$, shaded, altitude 2,250 $\mathrm{m})$, and from fallen tree leaves in another stream (width 0.4-1.5 m, water temperature $13.0^{\circ} \mathrm{C}$, shaded, altitude $1,860-1,970$ $\mathrm{m})$, both moderately flowing in natural forest. Associated species were S. (Gomphostilbia) guniki Takaoka, S. (N.) borneoense, S. (S.) alberti sp. nov. and S. (S.) liewi Takaoka.

REMARKS. Simulium (S.) aeneifacies was described from a unique female collected at Kamborangah $(2,160 \mathrm{~m}$ in altitude) of Mt. Kinabalu (Edwards, 1933), and its male, pupa and larva have remained to be unknown.

In this study, two streams near the type locality were surveyed and found to be colonized by several species of black flies including one species of the tuberosum species-group. This is identified as $S$. (S.) aeneifacies because the females reared from the pupae are morphologically in agreement with the loaned type specimen including the small sensory vesicle (Fig. 5A). This identification is also supported by the fact that this is the only species of this species-group breeding near the type locality (none of the other five related species treated in this study was collected near the type locality or from other areas with an elevation of 2,000 m or over).

Simulium (S.) aeneifacies is almost indistinguishable in the male from the two preceding new species but readily distinguished in the female by the smaller sen- sory vesicle (Fig. 5A). The pupa of this species is very similar to that of $S$. (S.) masilauense sp. nov. in most features including the arrangement of gill filaments (Fig. 5K) but seems to differ by the relative lengths of the thoracic trichomes, i.e., 2 dorsomedial trichomes (Fig. 5G) are short and slender and much shorter than the posterolateral trichomes (Fig. 5I) (2 dorsomedial trichomes (Fig. 4G) are long and stout, slightly longer than posteolateral trichome (Fig. 4I) in S. (S.) masilauense sp. nov.). The mature larva of $S$. (S.) aeneifacies is also very similar to those of $S$. (S.) alberti sp. nov. and $S$. (S.) masilauense sp. nov. but distinguished from both species by the dark marking of the ventral surface of the thoracic segment 3 broadly connected to that of the thoracic segment 1 (Fig. 9 I), and from S. (S.) masilauense sp. nov. by the ventral surface of the head capsule darkened only near lateral margins of the postgenal cleft (Fig. 10I).

\section{Simulium (Simulium) sabahense Smart and Clifford}

DESCRIPTION. Female. Almost indistinguishable from that of $S$. (S.) alberti sp. nov. except following features. Body length 1.6-1.8 $\mathrm{mm}$. Head. Frontal ratio $1.28-1.31: 1.00: 1.04^{-}$ 1.26 ; frons-head ratio $1.00: 3.45-3.72$. Frontoocular area moderately developed, directed laterally, with tip pointed. Labrum 0.54-0.61 times as long as clypeus. Proportional lengths of $3 \mathrm{rd}, 4 \mathrm{th}$, and 5 th segments of maxillary palp $1.00: 1.19-1.21: 2.67-2.94$. Sensory vesicle (Fig. 6A) elongate, of medium length, somewhat variable in size, $0.39-0.49$ times as long as 3rd maxillary palpal segment. Maxillary lacinia with 12 or 13 inner and $16-18$ outer teeth. Mandible with 26 inner and 8 or 9 outer teeth. Cibarium with 46-60 minute processes. Legs. Fore basitarsus moderately dilated, 4.91 times as long as greatest width. Hind basitarsus (Fig. 6B) yellowish-white on basal $3 / 5$ and medium brown on rest, 5.56 times as long as its greatest width, 0.82 and 0.64 times as wide as greatest widths of hind tibia and femur, respectively. Wing. Length $1.5 \mathrm{~mm}$. Genitalia. Sternite 8 covered with 8 or 9 long 

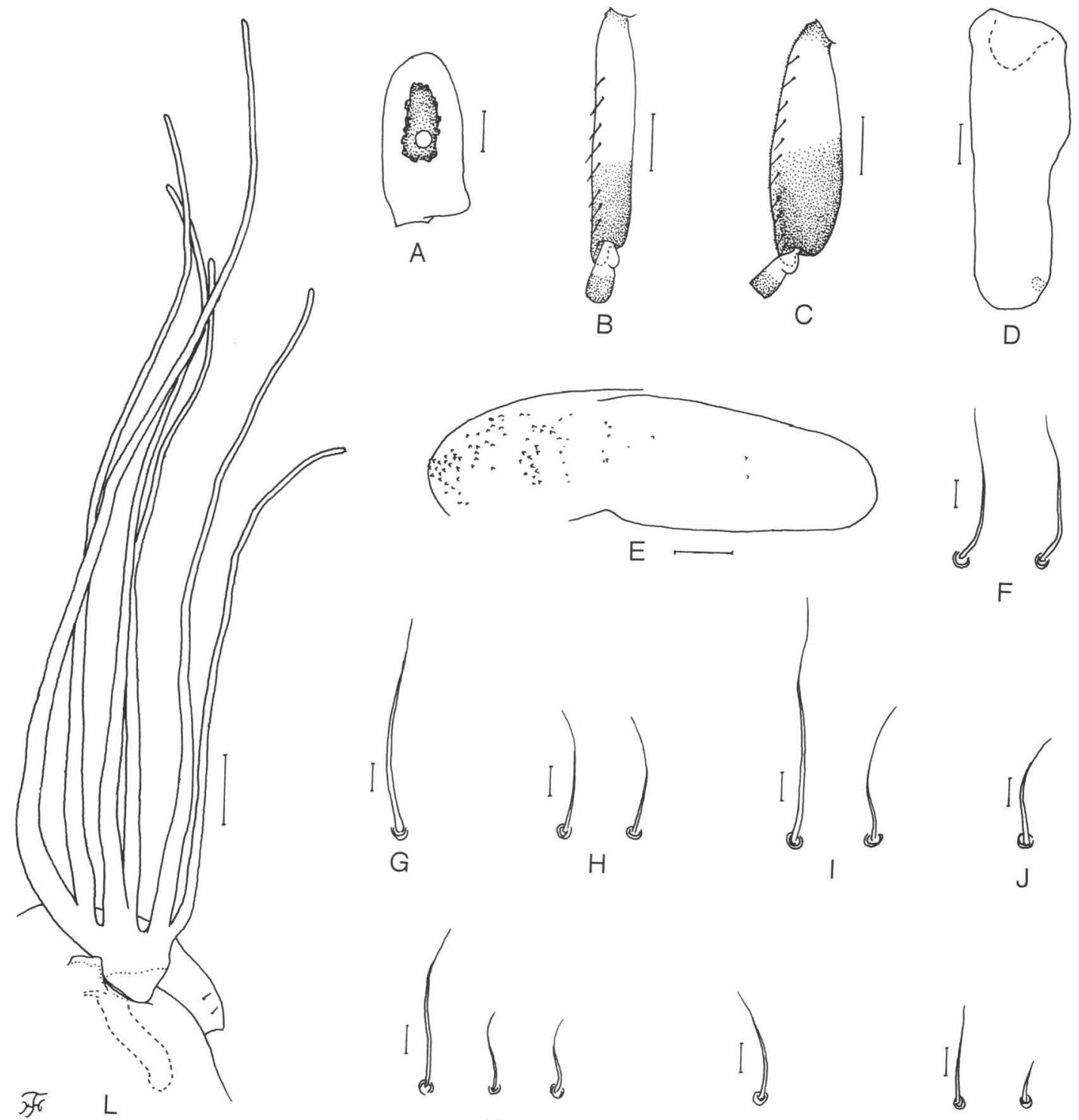

F
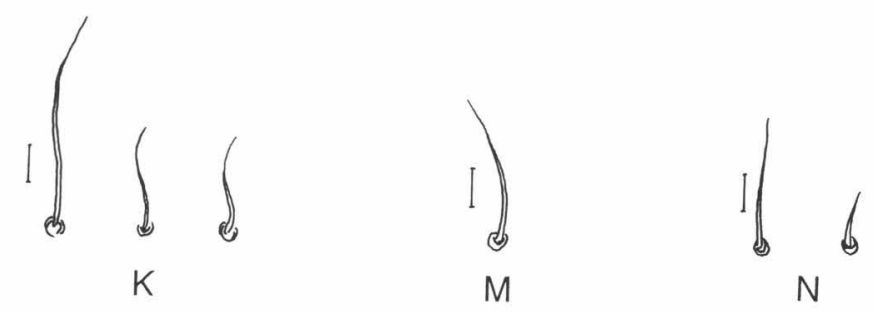

Fig. 6. Simulium (Simulium) sabahense Smort and Clifford. A, 3rd segment of female maxillary palp with sensory vesicle (right side; front view); B, basitarsus and 2nd tarsal segment of female hind leg (left side, outer view) C, basitarsus and 2nd tarsal segment of male hind leg (left side, outer view); D, style (ventrolateral view); E, antennal sheath of pupa (left side, front view); F, 2 frontal trichomes; G, facial trichome; $\mathrm{H}-\mathrm{K}$, trichomes on pupal thorax (H, mediodorsal; I, anterolateral; J, posterolateral; $\mathrm{K}$, ventrolateral); L, pupal gill filaments (left side, outer view); M, hair-like seta on dorsal surface of abdominal segment 1; N, 1 longer seta and 1 shorter seta on dorsal surface of abdominal segment 2. Scale bars. $0.1 \mathrm{~mm}$ for $\mathrm{B}, \mathrm{C}$ and $\mathrm{L} ; 0.04 \mathrm{~mm}$ for $\mathrm{E} ; 0.02 \mathrm{~mm}$ for A and D; $0.01 \mathrm{~mm}$ for F-K, M and N.

and medium-long stout hairs and a few short fine hairs on each side. Ovipositor valve with 4-6 short fine hairs. Paraproct in lateral view moderately produced ventrally, 1.4 times as wide as its basal length, covered with 14-22 medium-long stout hairs and numerous short fine hairs on lateral and ventral surface. Cercus in lateral view short, rounded posteriorly, 0.50 times as long as its greatest width, and covered with numerous medium-long and 
short stout hairs. Spermatheca ovoidal, 1.201.26 times as long as wide.

Male. Almost indistinguishable from that of $S$. (S.) alberti sp. nov. except following features. Body length $2.2 \mathrm{~mm}$. Head. Upper eye consisting of large facets in 12-14 vertical columns and in 13-15 horizontal rows on each side. First flagellomere of antenna 1.67 times as long as 2nd one. Proportional lengths of 3rd, 4th, and 5 th segments of maxillary palp $1.00: 1.35$ : 2.85. Sensory vesicle small, globular or ellipsoidal, 0.19 times as long as 3rd segment. Legs. Fore basitarsus moderately dilated, 5.70 times as long as its greatest width. Hind basitarsus (Fig. 6C) medium brown except basal $1 / 2$ yellowish-white, 3.32 times as long as its greatest width, 0.91 and 1.00 times as wide as greatest widths of hind tibia and femur, respectively. Wing. Length $1.6 \mathrm{~mm}$. Genitalia. Style in ventrolateral view (Fig. 6D) nearly parallelsided from base to basal $2 / 5$, then abruptly narrowed in middle, and nearly parallel-sided to apex. Ventral surface of 10th abdominal segment with 4-6 distinct hairs on each posterolateral corner. Cercus rounded, with 6 or 7 distinct hairs.

Pupa. Similar to that of $S$. (S.) masilauense sp. nov. except following features. Body length (excluding gill filaments) about $2.0 \mathrm{~mm}$. Head. Antennal sheath (Fig. 6E) moderately covered with minute cone-shaped tubercles on basal 1/3. Two frontal trichomes (Fig. $6 \mathrm{~F}$ ) mediumlong, subequal in length to each other, nearly as long as or little shorter than facial trichome (Fig. 6G). Thorax. Both of 2 dorsomedial trichomes medium-long and slender (Fig. 6H), 2 anterolateral trichomes different in length (Fig. 6I), 1 posterolateral trichome (Fig. 6J) mdium-long and as long as dorsomedial ones, ventrolateral trichomes composed of 1 medium-long and 2 short trichomes (Fig. 6K). Gill (Fig. 6L) with 6 slender thread-like filaments in pairs; all filaments lying vertically or slightly obliquely; longest dorsal filament 1.4$1.7 \mathrm{~mm}$, and shortest ventral filament $0.7-1.0$ $\mathrm{mm}$ long; stalks of dorsal and ventral pairs diverged basally at angle of 45-70 degrees.

Abdomen. Setae on dorsal surface of segments 1 and 2 as in Fig. 6M, N. Cocoon. $2.2-2.3 \mathrm{~mm}$ long by $0.8-1.0 \mathrm{~mm}$ wide.

Mature larva. Body length $3.8-4.3 \mathrm{~mm}$. Body color (Fig. 9J-L): thoracic segment 1 circled by dark grayish-brown to dark purplish-brown transverse wide band, thoracic segments 2 and 3 light grayish-brown dorsally; each of abdominal segments 1-4 circled by light grayish-brown to dark purplish-brown transverse wide band, and each of abdominal segments 5-8 almost entirely dark grayishbrown to dark purplish-brown (though often broken medially by unpigmented area on segments 7 and 8) dorsally and dorsolaterally, and each of abdominal segments 6 and 7 with wide area of similar color ventrally; intersegmental areas from thoracic segment 3 to abdominal segment 5 widely unpigmented. Cephalic apotome (Fig. 10J) yellow except anterior portion white, with head spots indistinct or faintly positive. Lateral surface of head capsule (Fig. 10K) almost entirely whitish-yellow except eye-spot region white, and narrow area above eyebrow often slightly darkened; all spots indistinct. Ventral surface of head capsule (Fig. 10L) whitish-yellow though often slightly darkened along each lateral margin of postgenal cleft; elongate spot on each side of postgenal cleft faintly negative, and narrow basal area on each side of postgenal cleft medium brown as usual. Cervical sclerite composed of 1 dark yellow to light brown elongate piece and 1 pale yellow small elliptical piece, not fused to occiput, widely separated medially from each other. Antenna composed of 3 segments and apical sensillum, much longer than stem of labral fan; proportional lengths of 1 st, 2 nd, and $3 \mathrm{rd}$ segments $1.00: 0.93-1.05: 0.65-0.78$. Labral fan with $36-38$ main rays. Mandible with mandibular serrations composed of 2 teeth; major and longer tooth at obtuse angle to mandible on apical side; supernumerary serration absent; comb-teeth decreasing in length from 1 st to 3rd. Hypostoma with 9 anterior teeth, median tooth and each corner tooth most prominent and subequal in length to one another, and intermediate teeth shorter and subequal in length to one another; lateral margins moderately serrate subapically; 4 or 5 hypostomal bristles slightly diverging posteriorly from lateral border on each side. Postgenal cleft (Fig. 10L) spade-shaped, deep (4.71-5.33 times as long as postgenal bridge), round laterally ( 0.34 -0.37 times as wide as head capsule). Thoracic cuticle almost bare. Abdominal cuticle almost bare except each side of anal sclerite moderately covered with short colorless setae. Rectal scales absent. Rectal organ compound, each lobe with 4-9 finger-like secondary lobules. Anal sclerite X-shaped, with broadened anteri- 
or arms $0.57-0.74$ times as long as posterior ones, with wide thinly-sclerotized extension between anterior arms; basal juncture area with open closed space medially or deep incision opening posteriorly; $1-3$ sensilla on basal juncture area and 5 or 6 sensilla posterior to posterior arms. Posterior circlet with $68-76$ rows of hooklets with up to 13 hooklets per row.

SPECIMENS EXAMINED. Two paratype pupal exuviae with cocoons, $\mathrm{BMNH}(\mathrm{E})$ 1969-429, mounted on the same slide, collected from tributary of East Masilau River, 5,500 feet, Mt. Kinabalu, Sabah, 4. Feb. 1964, by J. Smart; 2 paratype pupal exuviae with cocoons, $\mathrm{BMNH}(\mathrm{E})$ 1969-429, mounted on the same slide, collected from streams on TenomKeningau Road, Pegalan Valley, 600 feet, Sabah, 5-6 March, 1964, by J. Smart (these two pupae are reidentified as $S$. (S.) keningauense sp. nov. in this study); 2 females, 1 male, all reared from pupae and 1 pupal exuviae collected from a river, at Kipungit, inside Hot Spring Park, Poring, Sabah, 12.III.1998, by H. Takaoka and A. Takaoka; 1 male, reared from pupa, and 3 mature larvae collected from a small stream, inside Hot Spring Park, Poring, Sabah, 12.III.1998, by H. Takaoka and A. Takaoka; 5 females, 1 male, all reared from pupae, and 5 mature larvae collected from a river, Pueh, Sematan, Sarawak, 28.VIII. 2007, by H. Takaoka.

ECOLOGICAL NOTES. In Sabah, the pupae and larvae of this species were collected from tree leaves fallen in a rapidflowing river (width $7-10 \mathrm{~m}$, water temperature $22.0^{\circ} \mathrm{C}$, shaded, altitude 545-565 $\mathrm{m})$, and from fallen tree leaves in a moderately flowing small stream (width about $20 \mathrm{~cm}$, water temperature $23.0^{\circ} \mathrm{C}$, shaded, altitude $550 \mathrm{~m}$ ) in a natural forest; in Pueh, Sarawak, the pupae and larvae were collected from fallen tree leaves in a moderately flowing river (width 5-10 m, water temperature $24.0^{\circ} \mathrm{C}$, shaded). Associated species were $S$. (S.) maklarini Takaoka, $S$. (G.) mindoroense Takaoka and Tenedero in
Sabah, and S. (S.) lunduense sp. nov. and $S$. (S.) sp. in Sarawak.

REMARKS. Simulium (S.) sabahense was originally described from reared adults, pupae and mature larvae collected from various localities in Sabah and Sarawak by Smart and Clifford (1969). The variation in the relative size of the male hind basitarsus (much narrower than the hind tibia in one type, and nearly as wide as the hind tibia in the other) mentioned by Smart and Clifford (1969) strongly suggested the possibility that this species includes at least two species. In fact, two paratype pupal exuviae labelled "S. (S.) sabahense" collected from streams on Tenom-Keningau Road, Pegallan Valley, Sabah are different in the arrangement of gill filaments and the shape of tubercles on the thorax from the two other paratype pupal exuviae labelled "S. (S.) sabahense" collected from East Masilau River (type locality). In Sabah, the species name, $S$. (S.) sabahense, is applied in a restricted sense to the specimens from areas in and around the Kinabalu Parks (including Masilau, type locality of this species) which have a combination of the following two characteristics: i.e., six pupal gill filaments arranged in three pairs with short stalk and the number of the male enlarged upper eye-facets in 1214 vertical columns, as noted in the original description and illustration (Smart and Clifford, 1969). The two paratype pupal exuviae of "S. (S.) sabahense" collected from streams on Tenom-Keningau road are not $S$. (S.) sabahense but $S$. (S.) keningauense sp. nov. In Sarawak, several specimens collected from Pueh are reliably identified as $S$. (S.) sabahense. However, it is noteworthy that most specimens of the tuberosum species-group are not S. (S.) sabahense but $S$. (S.) lunduense sp. nov. in western parts and $S$. (S.) keningauense sp. nov. in eastern parts (e.g., Bario), both of which are easily distinguished from $S$. (S.) sabahense by the pupal thorax covered with cone-shaped tubercles and the rela- 
tively narrower male hind basitarsus, as mentioned later.

Simulium (S.) sabahense is similar at the adult stage to $S$. (S.) alberti sp. nov., S. (S.) masilauense sp. nov., and $S$. (S.) aeneifacies but barely distinguished from these related species by the darker female hind basitarsus (Fig. 6B) and the smaller number of male enlarged upper-eye facets (in 12-14 vertical columns and in 13-15 horizontal rows). The pupa of $S$. (S.) sabahense is very similar to those of $S$. (S.) masilauense sp. nov. and $S$. (S.) aeneifacies but distinguished from the latter two species by the antennal sheath moderately covered with cone-shaped tubercles on the basal $1 / 3$ (Fig. 6E) and the short posterolateral trichome (Fig. $6 \mathrm{~J}$ ) which is as long as the mediodorsal ones (Fig. 6H).

\section{Simulium (Simulium) keningauense sp. nov.}

DESCRIPTION. Female. Almost indistinguishable from that of $S$. (S.) alberti sp. nov. except following features. Body length 2.0-2.3 mm. Head. Frontal ratio $1.35-1.40: 1.00: 1.03-$ 1.16; frons-head ratio $1.00: 3.06-3.35$. Frontoocular area moderately developed, directed laterally, with tip pointed. Labrum $0.50-0.56$ times as long as clypeus. Proportional lengths of $3 \mathrm{rd}, 4 \mathrm{th}$, and 5 th segments of maxillary palp $1.00: 1.14-1.21: 2.43-2.49$. Sensory vesicle (Fig. 7A, B) elongate, $0.42-0.48$ times as long as 3rd maxillary palpal segment, with opening of moderate size. Maxillary lacinia with 14-17 inner and 18-22 outer teeth. Mandible with 28 or 29 inner and 10-12 outer teeth. Cibarium with 46 vestigial minute processes. Legs. Fore basitarsus moderately dilated, 4.41-4.88 times as long as greatest width. Hind basitarsus yellowish-white on basal $2 / 3$ or little more or less and medium brown on rest, 5.50-5.84 times as long as its greatest width, $0.69-0.78$ and $0.59-0.67$ times as wide as greatest widths of hind tibia and femur, respectively. Claw (Fig. 7C) with minute nodule-like projection near base. Wing. Length $1.7-1.8 \mathrm{~mm}$. Genitalia. Sternite 8 covered with 6-12 long and medium-long stout hairs and a few short fine hairs on each side. Ovipositor valve with 5 or 6 short fine hairs. Paraproct in lateral view covered with 18-24 medium-long stout hairs and numerous short fine hairs on lateral and ventral surface. Cercus in lateral view $0.56-0.61$ times as long as its greatest width. Spermatheca ovoidal, 1.20 times as long as wide.

Male. Almost indistinguishable from that of S. (S.) alberti sp. nov. except following features. Body length $1.9-2.3 \mathrm{~mm}$. Head. Upper eye consisting of large facets in 14 or 15 vertical columns and in 15-17 horizontal rows on each side. First flagellomere of antenna 1.55 times as long as 2 nd one. Proportional lengths of 3rd, 4 th, and 5th segments of maxillary palp 1.00 : 1.13-1.34:2.55-3.00. Sensory vesicle small, globular, 0.17-0.19 times as long as 3rd maxillary palpal segment, with small opening. Legs. Fore basitarsus moderately dilated, 5.52-5.55 times as long as its greatest width. Mid tibia medium to dark brown with base very narrowly yellow to light brown. Hind basitarsus (Fig. 7D) 3.81-3.89 times as long as its greatest width, $0.84-0.86$ and $0.84-0.86$ times as wide as greatest widths of hind tibia and femur, respectively. Wing. Length $1.5-1.6 \mathrm{~mm}$. Genitalia. Style in ventrolateral view (Fig. 7E) nearly parallel-sided from base to basal $2 / 5$, then gradually narrowed to apex. Ventral surface of 10th abdominal segment with 3 or 4 distinct hairs on each posterolateral corner. Cercus with 7-9 distinct hairs.

Pupa. Body length (excluding gill filaments)

Fig. 7. Simulium (Simulium) keningauense sp. nov. A and B, 3rd segment of female maxillary palp with sensory vesicle (right side; front view); C, claw of female hind leg; D, basitarsus and 2nd tarsal segment of male hind leg (left side, outer view); E, style (ventrolateral view); F and G, antennal sheath of pupa (left side, front view); H, 2 frontal trichomes; I, facial trichome; J, part of mediodorsal surface of pupal thorax showing cone-shaped tubercles between mediolongitudinal line and one of mediodorsal trichomes; $\mathrm{K}-\mathrm{N}$, trichomes on pupal thorax (K, mediodorsal; L, anterolateral; M, posterolateral; N, ventrolateral); O, pupal gill filaments (left side, outer view); $\mathrm{P}$ and $\mathrm{Q}$, basal part of pupal gill filaments ( $\mathrm{P}$, lateral view; $\mathrm{Q}$, dorsal view); $\mathrm{R}$, hair-like seta on dorsal surface of abdominal segment 1; S, 1 longer seta and 1 shorter seta on dorsal surface of abdominal segment 2. Scale bars.

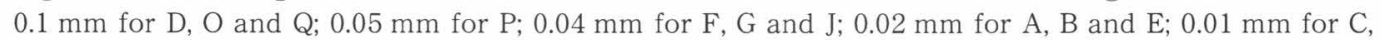
$\mathrm{H}, \mathrm{I}, \mathrm{K}-\mathrm{N}, \mathrm{R}$ and $\mathrm{S}$. 
Vol. 59 No. 22008
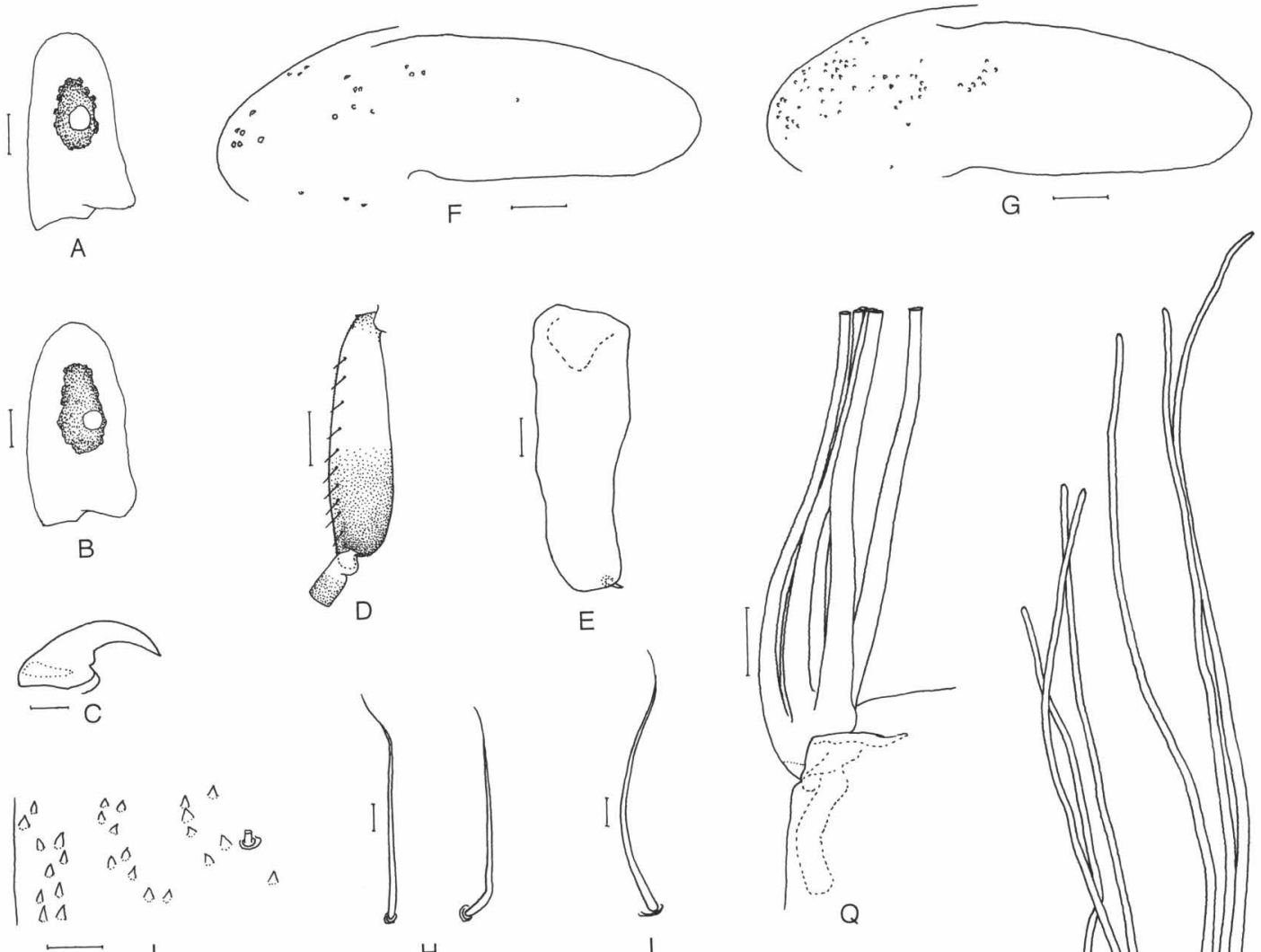

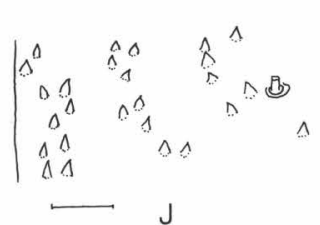
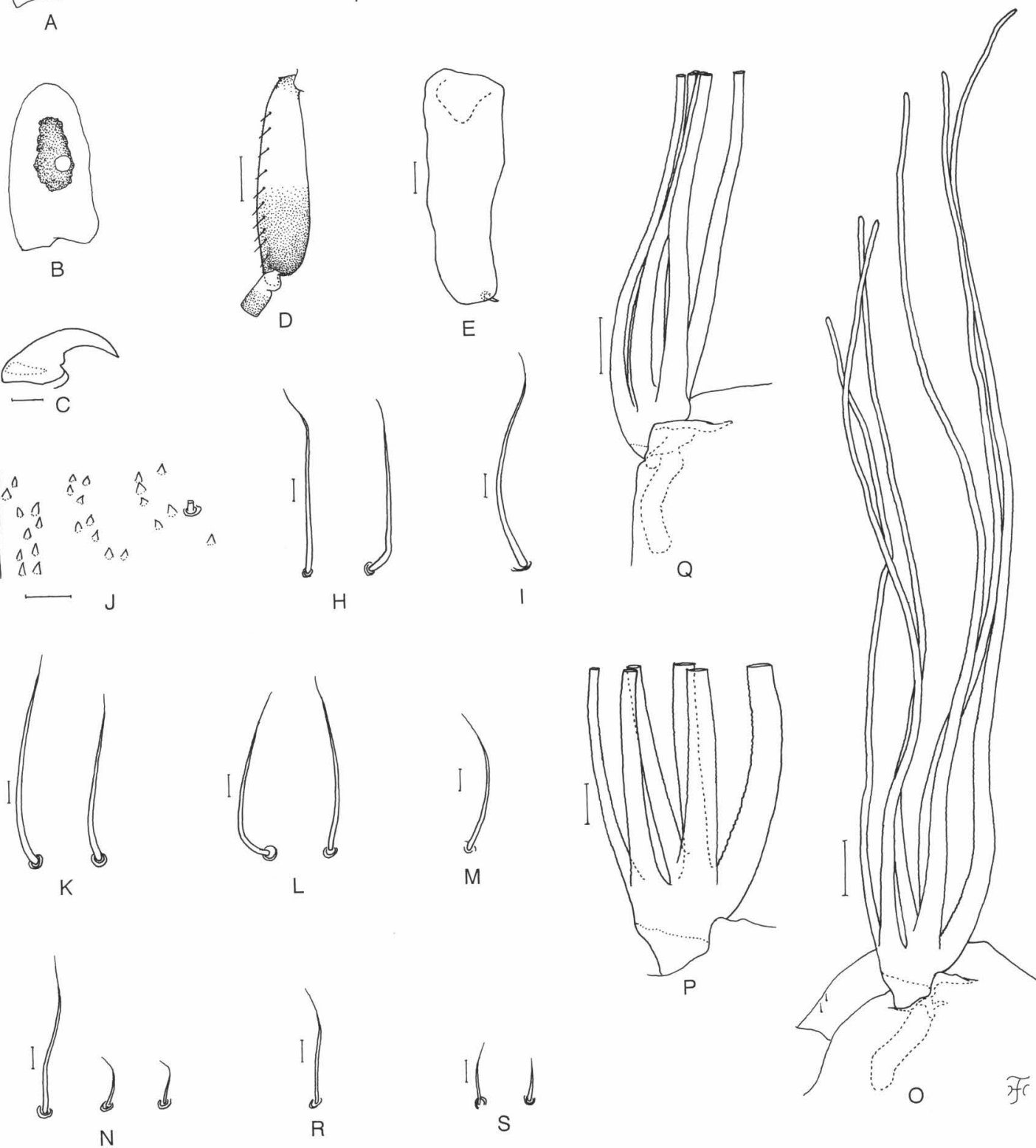
2.2-2.4 mm. Head. Integument yellowishbrown, moderately covered with round tubercles; antennal sheath (Fig. 7F, G) very sparsely to moderately covered with small round and cone-shaped tubercles near base: frons with 2 simple long stout trichomes (Fig. $7 \mathrm{H}$ ) on each side; face with 1 simple long stout trichome (Fig. 7I) on each side, which is slightly longer than frontal ones. Thorax. Integument yellowish-brown, moderately covered with cone-shaped tubercles with pointed apex (Fig. 7J) except anterior and and lateral surface mostly covered with round tubercles; thorax with 2 simple long stout trichomes mediodorsally (Fig. 7K), 2 simple long stout trichomes anterolaterally (Fig. 7L), 1 simple medium-long somewhat stout trichome posterolaterally (Fig. 7M), and 3 simple trichomes (1 long or medium-long and stout, 2 short and slender) ventrolaterally (Fig. $7 \mathrm{~N}$ ) on each side. Gill (Fig. 7O-Q) with 6 slender thread-like filaments arranged in $1+(1+2)+2$ filaments from dorsal to ventral (i.e., dorsal individual filament, 3 middle filaments consisting of 1 inner individual filament and 2 outer paired filaments, and 2 ventral paired filaments); middle and ventral pairs with very short stalk; all filaments medium brown, lying nearly vertically or slightly obliquely except 1 middle individual filament lying inside of middle paired filaments, and decreasing in length and thickness from dorsal to ventral; longest dorsal filament $1.4-1.9 \mathrm{~mm}$ long, and shortest ventral filament $0.7-1.2 \mathrm{~mm}$ long; dorsal and ventralmost filaments diverged basally at angle of about 40 degrees or little less; cuticular surface with distinct annular ridges and furrows throughout their length, covered with minute tubercles of different sizes, relatively larger ones on ridges and smaller ones on interridge spaces. Abdomen. As in S. (S.) alberti sp. nov. including setae on dorsal surface of segments 1 and 2 (Fig. 7R, S). Cocoon. As in S. (S.) alberti sp. nov.; $2.3-3.0 \mathrm{~mm}$ long by $1.0-1.2 \mathrm{~mm}$ wide.

Mature larva. Body length $3.8-4.3 \mathrm{~mm}$. Head capsule (Fig. $10 \mathrm{M}-\mathrm{O}$ ), thorax and abdomen (Fig. $9 \mathrm{M}-\mathrm{O}$ ) similar in color to those of $S$. (S.) sabahense. Antenna composed of $3 \mathrm{seg}$ ments and apical sensillum, slightly longer than stem of labral fan; proportional lengths of 1st, 2nd, and 3rd segments 1.00:0.91-0.95: 0.75-0.94. Labral fan with 34 main rays. Mandible with mandibular serrations composed of 2 teeth; major and longer tooth at obtuse angle to mandible on apical side; supernumerary serrations absent; comb-teeth decreasing in length from 1st to 3 rd. Hypostoma with 9 anterior teeth, median and corner teeth most prominent, subequal in length to each other; outer tooth of 3 intermediate teeth somewhat longer than middle and inner teeth which are subequal in length to each other; lateral margins moderately serrate subapically; 3 or 4 hypostomal bristles somewhat diverged posteriorly from lateral border on each side. Postgenal cleft (Fig. 10O) spade-shaped, deep (6.6-8.2 times as long as postgenal bridge), round laterally $(0.36-0.39$ times as wide as head capsule). Thoracic cuticle almost bare. Abdominal cuticle almost bare except dorsal surface of posterior segments sparsely covered with minute colorless setae, and each side of anal sclerite moderately covered with short colorless setae. Rectal scales absent. Rectal organ compound, each lobe with 7-10 fingerlike secondary lobules. Anal sclerite X-shaped, with broadened anterior arms 0.61-0.68 times as long as posterior ones, with wide thinlysclerotized extension between anterior arms; basal juncture area without incision posteriorly; 0-2 sensilla on basal juncture area and 5 or 6 sensilla posterior to posterior arms. Last abdominal segment with 2 bulges on each side, large lateral bulge and small ventrolateral one, latter visible as small ventral papillae when viewed laterally. Posterior circlet with 66-70 rows of hooklets with up to 13 hooklets per row.

TYPE SPECIMENS. Holotype female (with its associated pupal exuviae and cocoon), reared from a pupa collected from a stream at Ulu Senagang, Keningau, Sabah, Malaysia, 9.IX.2007, by H. Takaoka. Paratypes: 2 females, 3 males, all reared from pupae, 3 mature larvae, same data and date as those of the holotype; 7 females, 7 males, all reared from pupae, 3 mature larvae collected from a stream, near the entrance gate of Hot Spring Park, Poring, Sabah, 12.III.1998, by H. Takaoka and A. Takaoka; 6 females, 1 male, all reared from pupae, 3 mature larvae collected from an irrigation stream, Masilau, Sabah (same stream as noted under $S$. (S.) masilauense sp. nov.); 3 females, 2 males, 
all reared from pupae, and 5 mature larvae collected from Liwagu River, Kinabalu Parks, Sabah, 11.III.1998, by H. Takaoka and A. Takaoka; 4 females, 3 males, all reared from pupae, 5 mature larvae collected from a stream crossing the road from Bario to Pa Umur, Bario, Kelabit Highlands, northeastern part of Sarawak, 5.IX.2007, by H. Takaoka.

ECOLOGICAL NOTES. The pupae and larvae of this new species were collected from trailing grasses in a small stream (width $0.5-1.0 \mathrm{~m}$, water temperature $25.0^{\circ} \mathrm{C}$, shaded, altitude $400 \mathrm{~m}$ ) slowly flowing in a forest in Keningau, from grasses trailing in the water of a moderately flowing stream (width $3-6 \mathrm{~m}$, depth 0.2-0.4 m, water temperature $25.0^{\circ} \mathrm{C}$, exposed to sun, altitude $495 \mathrm{~m}$ ) in Poring, and from trailing grasses in a rapidly flowing irrigation stream (width about 1 $\mathrm{m}$, water temperature $14.0^{\circ} \mathrm{C}$, exposed to sun, altitude $1,880 \mathrm{~m}$ ) in Masilau, and from fallen tree leaves of a river (width 15-20 m (width of actual flowing water 2-4 m), water temperature $16.8^{\circ} \mathrm{C}$, shaded, altitude $1,445 \mathrm{~m}$ ) moderately flowing in a natural forest inside the Kinabalu Parks, and from bamboo leaves trailing in the water of a moderately-flowing stream (width 8$10 \mathrm{~m}$, depth $0.5-1.0 \mathrm{~m}$, water temperature $21.6^{\circ} \mathrm{C}$, exposed to sun, altitude about $1,000 \mathrm{~m}$ ) in Bario. Associated species were S. (G.) parahiyangum Takaoka and Sigit and $S$. $(G$.) rayohense Smart and Clifford in Keningau, S. (G.) parahiyangum and $S$. (S.) beludense Takaoka in Poring, S. (S.) aeneifacies in Liwagu River, S. (S.) masilauense sp. nov. in Masilau, and $S$. (G.) sp. nr. novemarticulatum Takaoka and Davies in Bario.

ETYMOLOGY. The species name keningauense refers to one of the the localities, Keningau, where this new species was collected.

REMARKS. Simulium (S.) keningauense sp. nov. differs from the preceding four related species in the male by the hind basitarsus which is narrower to some extent than the hind tibia and femur (Fig. 7D), and in the pupa by the arrangement of the gill filaments composed of $1+(1+2)$ +2 filaments (Fig. 7O-Q) as well as the thoracic integument mostly covered with cone-shaped tubercles (Fig. 7J).

The pupa of $S$. (S.) quasifrenum Delfinado described from Palawan Island (Takaoka, 1983) has the similar coneshaped tubercles on the dorsal surface of the thorax but differs from $S$. (S.) keningauense sp. nov. by the arrangement of the pupal gill filaments.

\section{Simulium (Simulium) lunduense sp. nov.}

DESCRIPTION. Female. Almost indistinguishable from that of $S$. (S.) alberti sp. nov. except following features. Body length 2.0-2.1 mm. Head. Frontal ratio $1.35-1.41$ : 1.00 : 1.05; frons-head ratio $1.00: 3.15-3.38$. Fronto-ocular area moderately developed, directed laterally, with tip pointed. Labrum $0.55-0.58$ times as long as clypeus. Proportional lengths of 3rd, 4 th, and 5 th segments of maxillary palp 1.00 : $1.09-1.12: 2.18-2.32$. Sensory vesicle (Fig. 8A) small, ellipsoidal, $0.35-0.38$ times as long as 3rd maxillary palpal segment, with opening of moderate size. Maxillary lacinia with 14-17 inner and 16-18 outer teeth. Mandible with 30 inner and 9 outer teeth. Cibarium with 44 minute processes. Legs. Fore basitarsus moderately dilated, $4.32-4.61$ times as long as greatest width. Hind basitarsus yellowishwhite on little less than basal $2 / 3$ and medium brown on rest, 5.56-5.69 times as long as its greatest width, $0.71-0.74$ and 0.57 times as wide as greatest widths of hind tibia and femur, respectively. Calcipala nearly as long as basal width, 0.34 times as wide as greatest width of basitarsus. Wing. Length $1.5-1.6 \mathrm{~mm}$. Genitalia. Sternite 8 covered with 6-10 long and medium-long stout hairs and a few short fine hairs on each side. Ovipositor valve with 4-7 short fine hairs. Stem of genital fork with somewhat flattened tip in some females. Paraproct in lateral view covered with $20-27$ medium-long stout hairs and numerous short fine hairs on lateral and ventral surface. Cercus in lateral view 0.63 times as long as its 
greatest width. Spermatheca ovoidal, 1.141.20 times as long as wide.

Male. Almost indistinguishable from that of $S$. (S.) alberti sp. nov. except following features. Body length $2.0-2.1 \mathrm{~mm}$. Head. Upper eye consisting of large facets in 12-14 vertical columns and in 13-16 horizontal rows on each side. First flagellomere of antenna 1.64-1.69 times as long as 2 nd one. Proportional lengths of $3 \mathrm{rd}, 4 \mathrm{th}$, and 5th segments of maxillary palp $1.00: 1.21-1.24: 2.41-2.60$. Sensory vesicle small, globular, 0.14-0.16 times as long as 3rd maxillary palpal segment, with small opening. Legs. Fore basitarsus moderately dilated, 5.406.00 times as long as its greatest width. Hind basitarsus (Fig. 8B) yellowish-white on little more than basal $1 / 2$, medium brown on rest, somewhat enlarged, nearly parallel-sided, 4.504.62 times as long as its greatest width, 0.720.74 and $0.68-0.70$ times as wide as greatest widths of hind tibia and femur, respectively. Calcipala nearly as long as basal width, 0.31 times as long as greatest width of basitarsus. Wing. Length $1.5-1.6 \mathrm{~mm}$. Genitalia. Style in ventrolateral view (Fig. $8 \mathrm{C}$ ) gradually narrowed from basal $1 / 3$ to apex. Ventral surface of 10th abdominal segment with 4-6 distinct hairs on each posterolateral corner. Cercus with 4-7 distinct hairs.

Pupa. Nearly as in S. (S.) keningauense sp. nov. except following features. Body length (excluding gill filaments) $2.0-2.2 \mathrm{~mm}$. Head. Antennal sheath (Fig. 8D) sparsely covered with small round and cone-shaped tubercles near base: frons with 2 simple long stout trichomes (Fig. 8E) on each side; face with 1 simple long stout trichome (Fig. 8F) on each side, which is as long as or slightly shorter than frontal ones. Thorax. Integument with 2 simple medium-long slender trichomes mediodorsally (Fig. $8 \mathrm{H}$ ), 2 simple slender trichomes (2 medium-long or 1 medium-long and 1 short) anterolaterally (Fig. 8I), 1 simple medium-long somewhat stout trichome posterolaterally (Fig. $8 \mathrm{~J})$, and 3 simple trichomes (1 medium-long and somewhat stout, 1 medium-long and slender, 1 short and slender) ventrolaterally (Fig. 8 K) on each side. Gill (Fig. 8L) with 6 slender thread-like filaments arranged in 3 pairs; stalk of each pair varying from short to long by gills and also by individual pupae as shown in Fig. 8 $\mathrm{M}-\mathrm{O}$; all filaments medium brown, lying nearly vertically or slightly obliquely, and decreasing in length and thickness from dorsal to ventral (though base of outer filament of middle pair nearly as thick as or slightly thicker than that of inner filament of dorsal pair in some pupae, and outer filament of ventral pair and inner filament of middle pair appear to be subequal in thickness to each other in most pupae; longest dorsal filament $1.3-2.0 \mathrm{~mm}$ long, and shortest ventral filament $0.7-1.3 \mathrm{~mm}$ long; dorsal and ventralmost filaments diverged basally at angle of 60-80 degrees. Abdomen . Setae on dorsal surface of segments 1 and 2 as in Fig. 8P, Q. Cocoon. Some cocoons extending ventrolaterally to some extent: $1.9-2.8 \mathrm{~mm}$ long by $0.9-1.4 \mathrm{~mm}$ wide.

Mature larva. Body length $3.7-4.2 \mathrm{~mm}$. Head capsule (Fig. 10P-R) and body (Fig. 9P-R) almost similar in color to those of $S$. (S.) keningauese sp. nov. except body color variable from dark gray to dark purplish-brown. Antenna composed of 3 segments and apical sensillum, slightly longer than stem of labral fan; proportional lengths of 1st, 2nd, and 3rd segments $1.00: 0.98-1.03: 0.75-0.77$. Labral fan with $36-40$ main rays. Mandible with mandibular serrations composed of 2 teeth; major and longer tooth at obtuse angle to mandible on apical side; supernumerary serrations absent; comb-teeth decreasing in length from 1st to 3rd. Hypostoma with 9 anterior teeth, corner teeth most prominent, followed by median tooth; middle tooth of 3 intermediate teeth shortest; lateral margins moderately

Fig. 8. Simulium (Simulium) lunduense sp. nov. A, 3rd segment of female maxillary palp with sensory vesicle (right side; front view); B, basitarsus and 2nd tarsal segment of male hind leg (left side, outer view); C, style (ventrolateral view); D, antennal sheath of pupa (left side; front view); E, 2 frontal trichomes; F, facial trichome; G, part of mediodorsal surface of pupal thorax showing cone-shaped tubercles between mediolongitudinal line and one of mediodorsal trichomes; $\mathrm{H}-\mathrm{K}$, trichomes on pupal thorax (H, mediodorsal; I, anterolateral; J, posterolateral; K, ventrolateral); L, pupal gill filaments (left side; outer view); $\mathrm{M}-\mathrm{O}$, basal parts of pupal gill filaments showing different lengths of stalks; $\mathrm{P}$, hair-like seta on dorsal surface of abdominal segment $1 ; \mathrm{Q}, 1$ longer seta and 1 shorter seta on dorsal surface of abdominal segment 2. Scale bars. $0.1 \mathrm{~mm}$ for B and $\mathrm{L} ; 0.05 \mathrm{~mm}$ for $\mathrm{M}-\mathrm{O} ; 0.04 \mathrm{~mm}$ for $\mathrm{D}$ and G; $0.02 \mathrm{~mm}$ for A and C; $0.01 \mathrm{~mm}$ for $\mathrm{E}, \mathrm{F}, \mathrm{H}-\mathrm{K}, \mathrm{P}$ and $\mathrm{Q}$. 


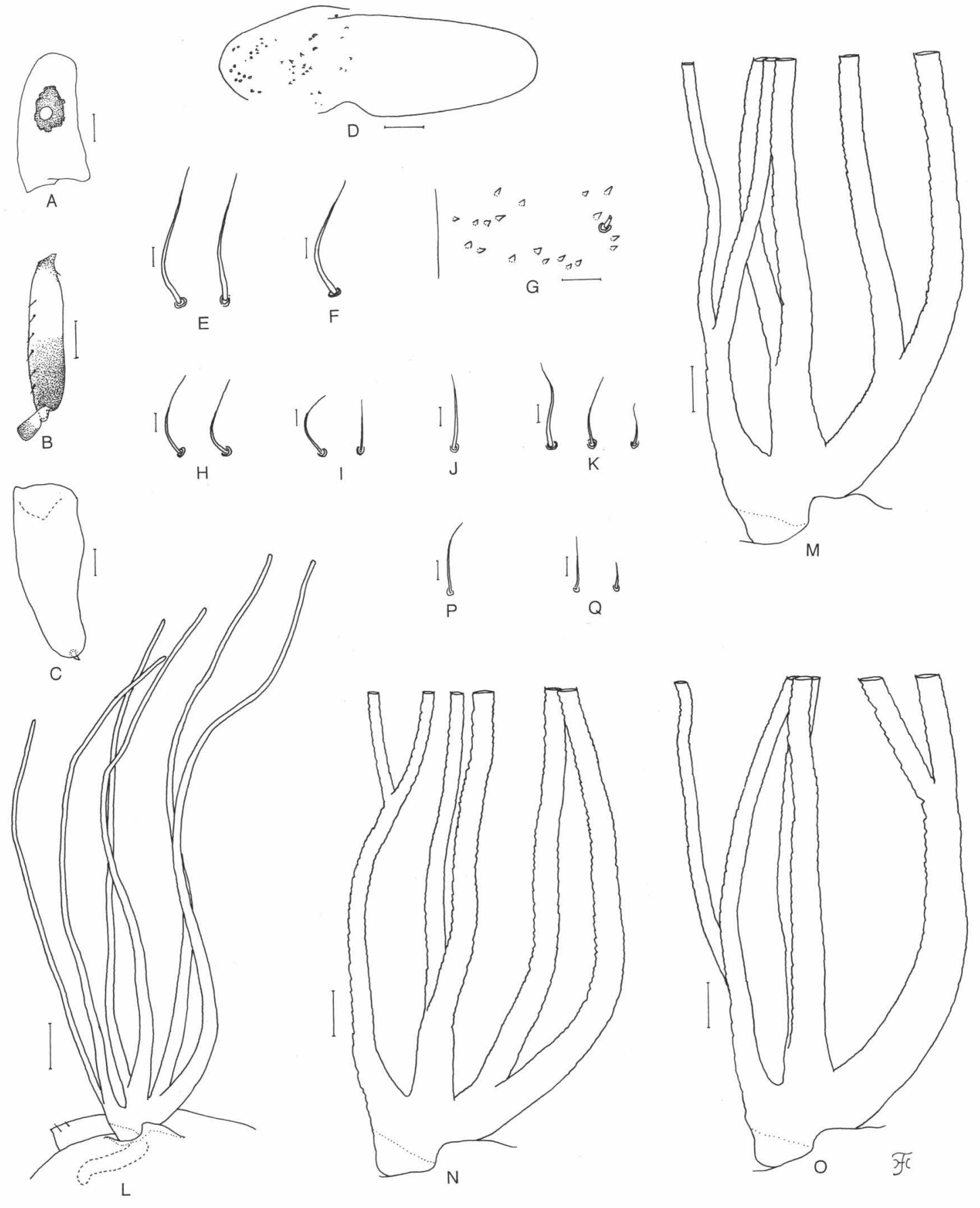




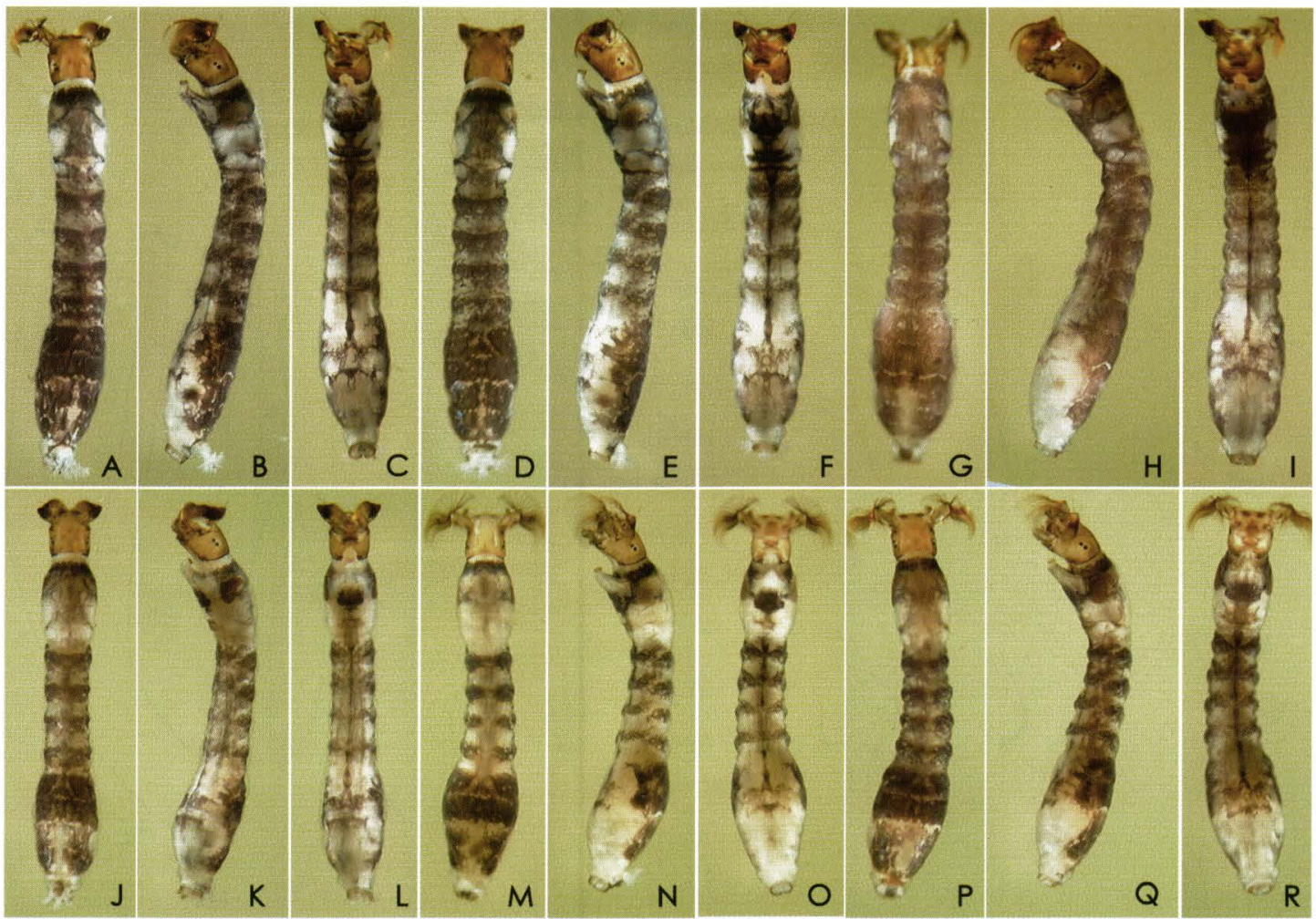

Fig. 9. Whole bodies of the mature larvae (dorsal, lateral and ventral view) of six Simulium species. AC, alberti sp. nov.; D-F, masilauense sp. nov.; G-I, aeneifacies; J-L, sabahense; $\mathrm{M}-\mathrm{O}$, keningauense sp. nov.; $\mathrm{P}-\mathrm{R}$, lunduense sp. nov.
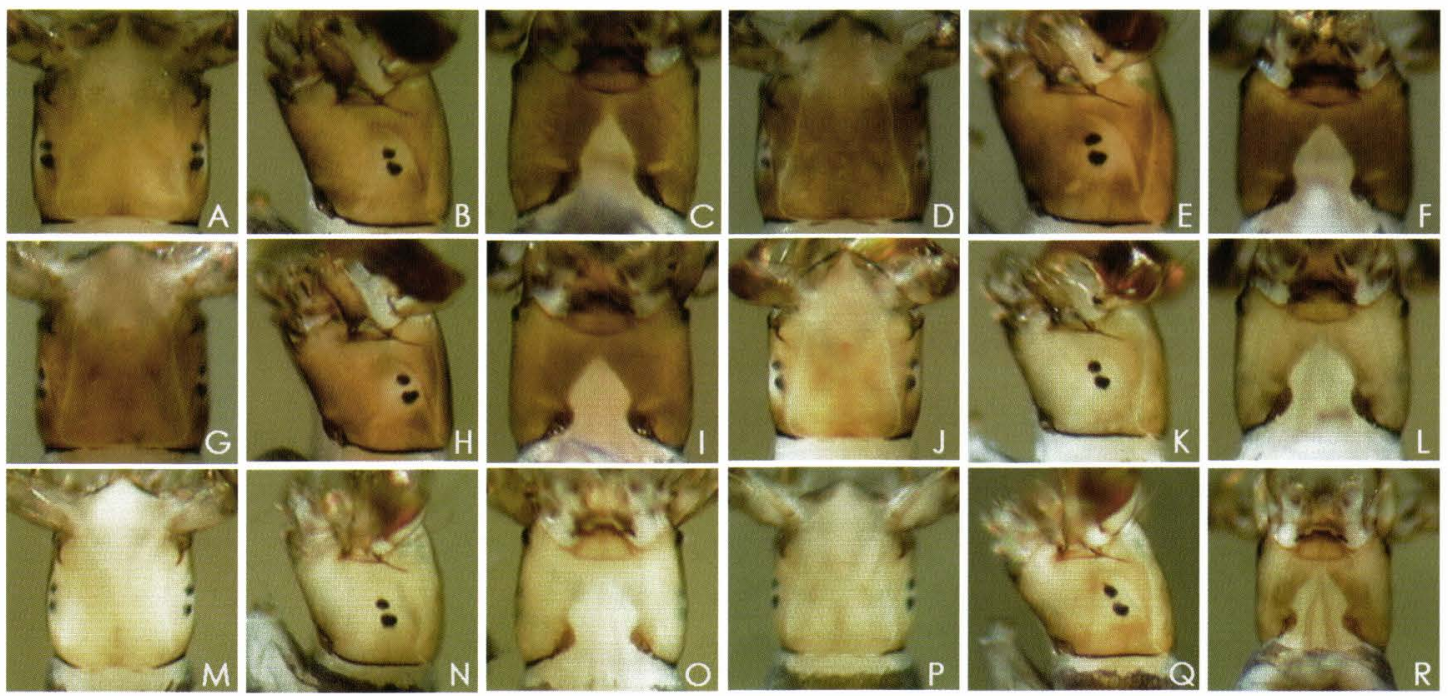

Fig. 10. Head capsules of the mature larvae (dorsal, lateral and ventral view) of six Simulium species. A-C, alberti sp. nov.; D-F, masilauense sp. nov.; G-I, aeneifacies; J-L, sabahense; M-O, keningauense sp. nov.; $\mathrm{P}-\mathrm{R}$, lunduense sp. nov. 
serrate subapically; 4-6 hypostomal bristles somewhat diverging posteriorly from lateral border on each side. Postgenal cleft (Fig. 10R) spade-shaped, deep (7.6 times as long as postgenal bridge), round laterally (0.38-0.39 times as wide as head capsule). Thoracic cuticle almost bare. Abdominal cuticle almost bare except dorsal surface of posterior segments sparsely covered with minute colorless setae, and each side of anal sclerite moderately covered with short colorless setae. Rectal scales absent. Rectal organ compound, each lobe with 8-11 finger-like secondary lobules. Anal sclerite X-shaped, with broadened anterior arms 0.75 times as long as posterior ones, with wide thinly-sclerotized extension between anterior arms; basal juncture area without incision posteriorly; $0-2$ sensilla on basal juncture area and 4-6 sensilla posterior to posterior arms. Last abdominal segment somewhat bulged ventrolaterally, forming small ventral papillae visible from side. Posterior circlet with $76-78$ rows of hooklets with up to 16 hooklets per row.

TYPE SPECIMENS. Holotype female (with its associated pupal exuviae and cocoon), reared from a pupa collected from a river at Lundu, Sarawak, 18.III.1998, by H. Takaoka and A. Takaoka. Paratypes: 4 females, 9 males, all reared from pupae, 4 mature larvae, same data and date as those of the holotype; 6 females, 3 males, all reared from pupae, and 3 mature larvae collected from Bunga River, Bunga, Sarawak, 16. III. 1998, by H. Takaoka and A. Takaoka; 16 females, 13 males, reared from pupae, and 5 mature larvae collected from Cina River, Cina, Sarawak, 17. III. 1998, by H. Takaoka and A. Takaoka; 1 female, 1 male, each reared from pupa, collected from a river, Pueh, Sematan, Sarawak, 28.VIII.2007, by H. Takaoka.

ECOLOGICAL NOTES. The pupae and larvae of this new species were collected from trailing grasses in a river (width about $10 \mathrm{~m}$, water temperature $26.0^{\circ} \mathrm{C}$, exposed to sun, altitude about $10 \mathrm{~m}$ ) at Lundu, from trailing grasses in the Bunga River (width 2-5 m, water temperature $26.0^{\circ} \mathrm{C}$, exposed to sun) moderately flowing in a cacao plantation, from trailing grasses in the Cina River (width 15-20 m, water temperature $25.0^{\circ} \mathrm{C}$, exposed to sun, altitude about $80 \mathrm{~m}$ ), and from fallen tree leaves in a moderately flowing river (width 5-10 m, water temperature $24.0^{\circ} \mathrm{C}$, shaded) in Pueh. Associated species were S. (G.) mindoroense, S. (S.) sabahense and S. (S.) sp.

ETYMOLOGY. The species name lunduense refers to the name of the place, Lundu, where this new species was collected.

REMARKS. Simulium (S.) lunduense sp. nov. seems to be closely related to $S$. (S.) keningauense sp. nov. in that both species have the male hind basitarsus which is always narrower than the hind tibia and femur (Fig. 8B), and the pupal thorax mostly covered with cone-shaped tubercles (Fig. 8G), but readily distinguished from the latter in the female by the simple claw without a minute subbasal projection, in the male by the style tapered toward the apex in ventrolateral view (Fig. $8 \mathrm{C}$ ) as well as the much narrower hind basitarsus (Fig. 8B), and in the pupa by the arrangement of the gill filaments (Fig. 8L-O). This new species is similar to S. (S.) sabahense in having the smaller number of the male enlarged eye-facets, and the pupal gill filaments arranged in three pairs with very short stalk like Fig. 8 $\mathrm{L}$ (one of the variable arrangements found in S. (S.) lunduense sp. nov.), but differs from the latter species by the cone-shaped tubercles on the dorsal surface of the pupal thorax (Fig. 8G).

\section{ACKNOWLEDGEMENTS}

I am grateful to Prof. Yon Hoi Sen, Malay University, for his kind help and arrangements for collections of black flies in Sabah and Sarawak in 1998. Thanks are due to Dr. Charles Leh, M.U., Sarawak Museum, Kuching, who kindly arranged 
field surveys in Sarawak in 1998 and 2007, Dr. Lo Albert, Sabah Museum, Kota Kinabalu, and Dr. Maklarin Bin Lakim, Kinabalu Conservation Center, Kinabalu Parks, for their kind arrangements in the field collections in 2007 in Keningau and in and around Mt. Kinabalu, respectively. My appreciation goes to Mr. Jesius Gantor, Mr. Patrick Francis, Sabah Museum, and Mr. Yusilie Bin Kumin, Kinabalu Conservation Center, Kinabalu Parks, who kindly helped in the field surveys in Sabah in 2007. The field collections of black flies in Sarawak in 2007 were carried out in the framework of the Research project "Study on taxonomy and bionomics of two winged flies, Diptera, in Sarawak, East Malaysia" initiated by the Japanese team (Representative, Dr. Ichiro Miyagi, Professor Emeritus of University of the Ryukyus) and Entomology Section of Sarawak Museum (Representative, Dr. Charles Leh, M.U.) under the permission of the Sarawak State Department of Forestry. I like to thank Ms. Theresa Howard, the Natural History Museum, London, U.K., for her kind loan of the type specimens needed for this study, and Ms. Chiharu Aoki, Oita University, for her kind help in taking photographs of larval bodies and head capsules. I sincerely thank Dr. Charles Leh, M.U. for his kindness in reading the manuscript and giving valuable comments. This study was in part supported by a Grant-in-Aid for Oversea Research from the Japan Society for the Promotion of Science (No. 18406011).

\section{REFERENCES}

Edwards, F. W. 1933. Diptera Nematocera from Mount Kinabalu. J. fed. Malay St. Mus., 17: 223296.

Smart, J. and Clifford, E. A. 1969. Simuliidae (Diptera) of Sabah (British North Borneo). Zool. J. Linn. Soc., 48: 9-47.

Takaoka, H. 1983. The Blackflies (Diptera: Simuliidae) of the Philippines. xi+199 pp., Japan Society for the Promotion of Science, Tokyo.

Takaoka, H. 2001a. Two new and three newly recorded species of black flies (Diptera: Simuliidae) from Sabah, Malaysia. Jpn. J. Trop. Med. Hyg., 29: 221-230.

Takaoka, H. 2001b. Description of two new species of black flies (Diptera: Simuliidae) from Sarawak, Malaysia. Jpn. J. Trop. Med. Hyg., 29: 243-252.

Takaoka, H. 2003. The Black Flies (Diptera: Simuliidae) of Sulawesi, Maluku and Irian Jaya. xxii + 581 pp., Kyushu University Press, Fukuoka.

Takaoka, H. 2007. Two new species of Simulium (Simulium) from Sabah, Malaysia (Diptera: Simuliidae). Med. Entomol. Zool., 58: 291-301.

Takaoka, H. and Davies, D. M. 1995. The Black Flies (Diptera: Simuliidae) of West Malaysia. viii +175 pp., Kyushu University Press, Fukuoka. 